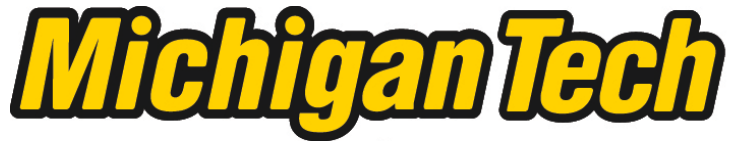 \\ Michigan Technological University Create the Future Digital Commons @ Michigan Tech
}

Dissertations, Master's Theses and Master's Reports - Open

Dissertations, Master's Theses and Master's

Reports

2015

\section{THE ROUTINE DISASTER: A CASE STUDY IN EL SALVADOR}

Tyler M. Barton

Michigan Technological University

Follow this and additional works at: https://digitalcommons.mtu.edu/etds

Part of the Geology Commons, Hydrology Commons, and the Other Social and Behavioral Sciences Commons

Copyright 2015 Tyler M. Barton

\section{Recommended Citation}

Barton, Tyler M., "THE ROUTINE DISASTER: A CASE STUDY IN EL SALVADOR", Master's Thesis, Michigan Technological University, 2015.

https://doi.org/10.37099/mtu.dc.etds/997

Follow this and additional works at: https://digitalcommons.mtu.edu/etds

Part of the Geology Commons, Hydrology Commons, and the Other Social and Behavioral Sciences Commons 
THE ROUTINE DISASTER: A CASE STUDY IN EL SALVADOR

\author{
By
}

Tyler M. Barton

\begin{abstract}
A THESIS
Submitted in partial fulfillment of the requirements for the degree of MASTER OF SCIENCE

In Geology
\end{abstract}

MICHIGAN TECHNOLOGICAL UNIVERSITY

2015

C 2015 Tyler M. Barton 
This thesis has been approved in partial fulfillment of the requirements for the Degree of MASTER OF SCIENCE in Geology.

Department of Geological and Mining Engineering and Sciences

\section{Thesis Advisor: $\quad$ Wayne Pennington}

Committee Member: John Gierke

Committee Member: Carol MacLennan

Department Chair: John Gierke 


\section{Table of Contents}

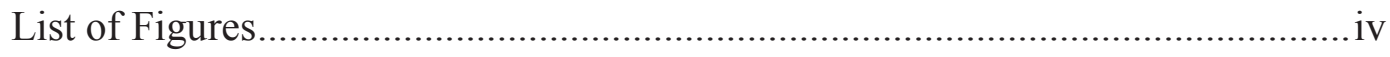

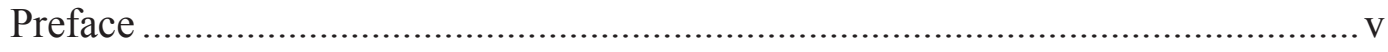

Acknowledgements ............................................................................... vi

List of Abbreviations .................................................................................. vii

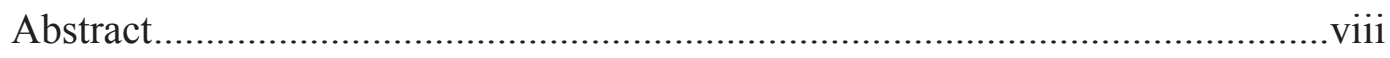

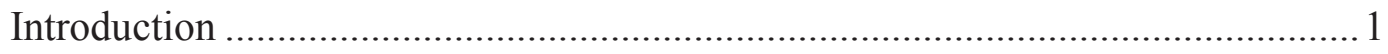

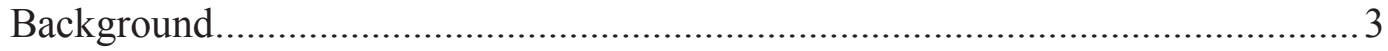

Geographic and geologic setting ................................................. 4

Community setting .......................................................................... 5

Goals of the research ................................................................................ 7

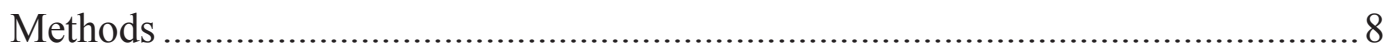

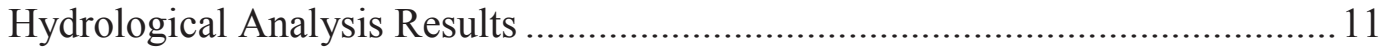

HEC-HMS simulation ................................................................. 12

Model simulations of parameter sensitivity .........................................20

Remote sensing interpretation and validation ......................................25

Community Perspective and Interview Findings ........................................... 27

Case study: Tropical Depression 12-E ................................................28

Household strategies to manage risk brought on by floods.................... 31

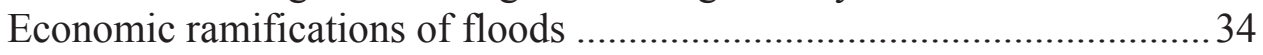

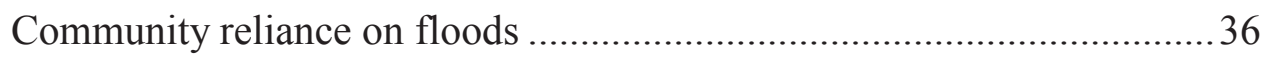

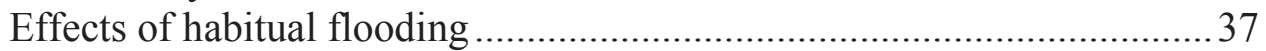

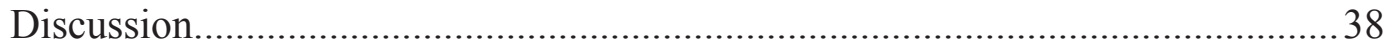

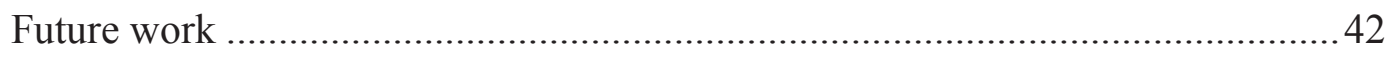

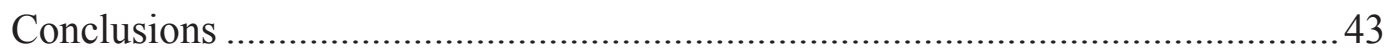

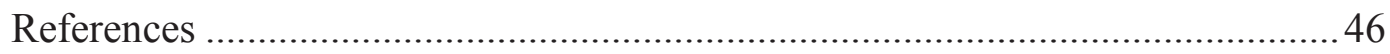

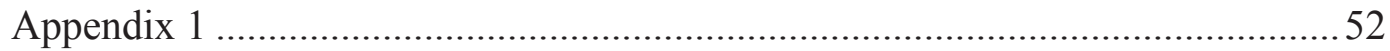

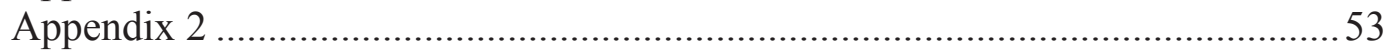

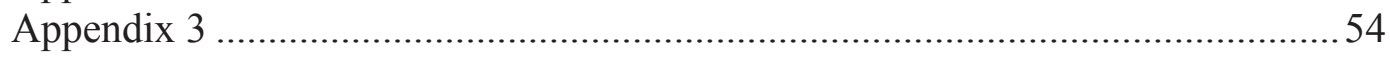

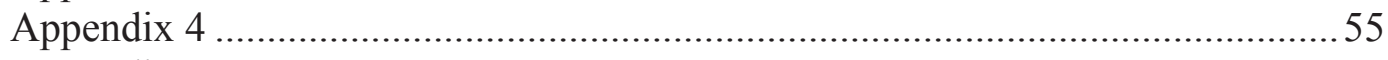

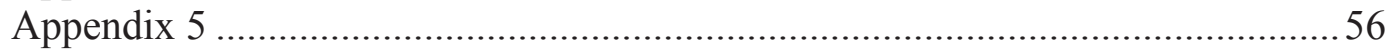




\section{List of Figures}

Figure 1: Map of El Salvador and Central America ............................................. 4

Figure 2: Satellite image of the eastern region of E1 Salvador .................................

Figure 3: Detailed satellite image of community of El Borbollón ............................ 7

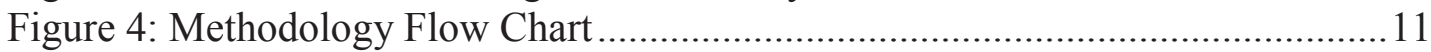

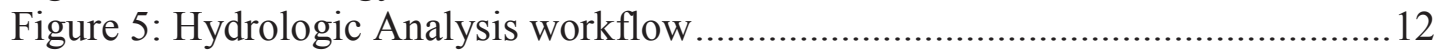

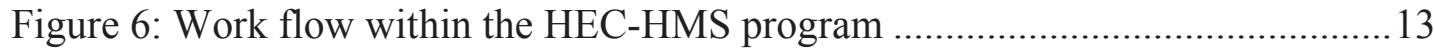

Figure 7: Location and extent of basin analyzed in HEC-HMS .............................. 16

Figure 8: Modeled flow spanning Tropical Depression 12-E ................................. 18

Figure 9: Cumulative Inflow volume, cumulative Outflow volume, and Net volume

of water in the Lower sub-basin on a given day ......................................19

Figure 10: Detail of DEM in the lower sub-basin ...............................................20

Figure 11: DEM derived relationship between surface area and depth....................21

Figure 12: Volumetric increase in the lagoon waters as it relates to depth ................21

Figure 13: Results of sensitivity analysis ........................................................23

Figure 14: Additional simulation results using varied rainfall distribution patterns

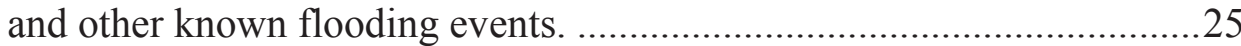

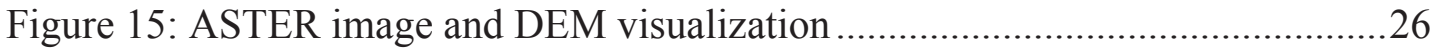

Figure 16: Questionnaire used in survey of local residents....................................54 


\section{Preface}

All text and figures were prepared by the author and advising committee: Dr. Wayne Pennington, Dr. John Gierke, and Dr. Carol MacLennan. Dr. Miriam Rios processed the original ASTER satellite imagery, and aided in its interpretation. The original direction for this work was largely based on suggestions from Dr. John Gierke and the residents of El Borbollón, who expressed interest in better understanding the flooding and disaster aid processes taking place in their community. 


\section{Acknowledgements}

I'd like to thank the US National Science Foundation for partial financial support, in the form of the PIRE grant, number 0530109.

My advisor, Dr. Wayne Pennington, and my committee members Dr. John Gierke and Dr. Carol MacLennan.

Dr. Miriam Rios for helping with the satellite image downloading and processing, and interpretation. Dr. Rudiger Escobar Wolf for being a sounding board and letting bounce ideas off of him.

The US Peace Corps and especially their staff in El Salvador for their support and understanding in this project. The entire Peace Corps volunteer group, my friends in El Borbollón, and my host family.

The government scientists of El Salvador's Servicio Nacional de Estudios Territoriales (SNET), now known as Dirección General del Observatorio Ambiental (DGOA).

And of course to all my friends and family within the Michigan Tech community, particularly those in the PCMI program. 


\title{
List of Abbreviations
}

\author{
ASL - Above Sea Level \\ ASTER - Advanced Spaceborne Thermal Emission and Reflection Radiometer \\ DEM - Digital Elevation Model \\ DPM - Disaster Prevention and Mitigation \\ GIS - Geographic Information System \\ GPS - Global Positioning System \\ HEC-HMS - Hydrologic Engineering Center - Hydrologic Modeling System \\ NGO - Non-governmental Organization \\ NHC - National Hurricane Center \\ SNET - Servicio Nacional de Estudios Territoriales \\ UN - United Nations \\ UNDP - United Nations Development Programme \\ UNDAC - United Nations Disaster Assessment and Coordination \\ USD - United States Dollar
}




\begin{abstract}
A 2010 report by the UN Disaster Assessment and Coordination ranked El Salvador as the most vulnerable country in the world to natural disasters, with roughly $95 \%$ of the population at risk. The combination of recurring natural disasters and high vulnerability in a relatively small country has led to repeated exposure of local residents to significant natural phenomena of all sorts, including earthquakes, flooding, landslides, volcanic eruptions, and hurricanes.

The effect of disaster assistance can be multi-faceted and this report examines the case of flooding hazards of a small town in the south-eastern San Miguel region of the country, called El Borbollón, in which assistance seems to have become a natural part of the local economy. . This community sits at the base of a large watershed. Wet season flooding events raise the lake levels by 1 to 3 meters almost every year, completely submerging the town's main road. Occasional 4 to 6 meter flooding events cause the evacuation of $1000+$ community members; this occurred most recently during Tropical Depression 12-E in the 2011 wet season.

I argue that a purely hydrological approach to assessing the local flood hazard is insufficient. First, I evaluate the magnitude of the Tropical Depression 12-E flooding event via HEC-HMS computer modeling and GIS, coupled with an analysis of ASTER satellite imagery. Parallel hazard and vulnerability analyses were conducted, and I describe my findings from a social research perspective. I find that locals have largely decided to co-exist with this recurring flood event, because they have much to gain by living in a perpetually at-risk condition, through the benevolence of aid organizations. This exposes a fundamental question: is it still a disaster if it is routine? By examining the role that large-scale flooding events play on the lives of local inhabitants, we present examine a scenario that more closely represents the multifaceted reality in which we live.

Similar situations likely exist elsewhere, and lessons learned here may be more broadly applicable. The existence of a routine disaster means revisions might be necessary to government, scientist, and aid organization strategies.
\end{abstract}




\section{Introduction}

Flooding events are among the world's most dangerous natural hazards, averaging 6,300 deaths and over $\$ 30$ billion USD in damages per year over the past decade (IFRC, 2014). In the future, sea level rise, extreme rain fall, and other consequences of global climate change will undoubtedly lead to an increase in flooding disasters (Mirza, 2003). While these hazards increase, the vulnerability of communities will increase as well. This is especially true as human populations grow and infringe upon areas prone to flooding. Understanding past and potential future flooding hazards of a given area can better prepare at-risk communities, reducing fatalities and the loss of infrastructure.

The joint perspective of both social sciences and flood hazard mitigation sciences is vital to a holistic understanding of a natural disaster and its effects. Characterizing floods is typically accomplished through the use of hydrologic modeling, a purely physical-science approach to assessing hazard. These models provide us with vital information, such as the physical dimensions and reach of the flood waters, as well as changing volumes of water over time. They provide us with the "where" and the "when." However, social sciences are a necessary component when attempting to paint a more complete picture of the situation. They take a different but equally rigorous approach, by looking at these technological models and examining how they apply to real life scenarios. Physical modeling results in quantifiable predictions such as probable risk percentages and detailed hazard zone delineations but do not include the human factor. Because risk is perceived in different ways by different people and communities, and does not always equate to fear, a calculation of risk does not provide sufficient insight for response agencies. An analyses of the social dynamics at play gives us the "who" and the "why." The combination of both physical science and social science gives us the "what" - and better insight into the need for relief or how best to deliver it.

Combining both approaches provides a result that better communicates the level of hazard to a wider range of audience. For example, precise outcomes of the combined modeling can be directly applied to saving lives and reducing risk for those living within the flood zone, as well used by emergency action planners when analyzing logistics for local preparation purposes. A map produced at a less detailed scale is still potentially of use for scientists conducting regional or national level hydrological studies, or even for local government policy makers with the purpose of implementing new constructions guidelines in the area. The social research is useful, in part, for aid charities, NGOs, and grant organizations in how they will allocate appropriate levels of disaster relief handouts to those most in need.

This work aims to fill the gap in the literature regarding the realities and complexities of flood hazard modeling. I believe that a combination of geological and social sciences methodologies is vital to accurately addressing this need. This project is an attempt to evaluate the effectiveness of this combination modeling such that it benefits policy, government officials, and the affected community. By observing a case study, we will look at the usefulness of a social assessment of a flooding event and disaster planning. Specifically, the research presented will examine ways in which hydrological modeling may or may not be augmented by the inclusion of social 
research at an early stage, in an effort to model scenarios more representative of the multifaceted reality in which we live. I will do this by focusing on the short and long term community response to an extreme flooding event experienced by the town of El Borbollón, El Salvador, during a meteorological even known as Tropical Depression 12-E, which occurred in October of 2011.

Hydrological assessment is typical done through transport modeling of groundwater flow and transport mechanisms, and physically-based water catchment systems (O’Connell \& Todini, 1996). This has proved vital in watershed characterization, water resources planning and management, and understanding the factors that influence the nature of flooding.

However, a holistic model requires inputs from both social and hydrological sciences. Work has been done in this field, and has already provided useful results. Smith and Freedy (2000) showed that both psychological and physical wellbeing were increased in the long-term when post-disaster programs were implemented to prevent the loss of psychosocial resources (such as one's routine, self-esteem, optimism, and accomplishment of goals). Additionally, blending natural disaster modeling with a social sciences perspective has proven fruitful in the past for improved risk assessment (Hoffman \& Oliver-Smith, 2002; Jonkman et al., 2008; Paton et al, 2008; Lugeri et al., 2010), arguably helping saves lives. These concepts have all looked at risk in a very broad manner, and have tended to focus on general natural hazards. Few have focused on blending social sciences solely with flood modeling at the initial stages of the model, as this thesis attempts to do.

Social science studies have already revealed some of the intricate situations which can present themselves during a natural disaster. For example, studies show that official warnings are often not enough of a motivation for evacuation during a disaster (Slovic, 1987; Wildavsky \& Dake, 1990; Dash \& Gladwin, 2007). Essentially, this stems from a lack of communication between scientists and general public. While accurate models, theories, and best practices are created, they are seldom presented in useful and culturally sensitive ways to those who need them. Part of the problem could be a lack of education on part of the public. It could also originate from public distrust towards scientists or officials. Whatever the underlying reasons, understanding who is affected, and why they will or will not follow standard emergency practices, is of the utmost importance.

One area where studying flooding hazards is paramount to reducing risk is in El Salvador, which has been ranked by the United Nations Disaster Assessment and Coordination agency as the world's most vulnerable country to natural disasters (UNDAC, 2010), affected by floods, earthquakes, landslides, volcanic eruptions, hurricanes, and tsunamis. According to this report, 95\% of the country's population lives in high-risk areas, and "El Salvador will experience an increase in frequency and severity of natural hazards as a result of climate change, particularly in relation to extreme rainfall," leading to more common and more intense flooding as well as other "devastating consequences including economic and human loss."

The following study presents information about the community and its environs, before describing the objectives of the research and respective methods employed. After a parallel investigation, in which a case study approach is used to 
illustrate the relationship between flooding hazards and a local community, the usefulness of the fusion of social data into hydrological modeling is discussed.

\section{Background}

Devastated by a 12 year civil war (1979-1992), El Salvador remains one of the 10 poorest countries in Latin America (Dilley et al., 2005; UNDAC, 2010). It is also Central America's most densely populated country with 290 people per square kilometer (UN, 2015). The country's notable social, economic, and environmental vulnerabilities will almost certainly be aggravated by climate change in the years to come. One such site within the country is the small town of El Borbollón, located in the eastern department of San Miguel (Figure 2 and Figure 3). El Borbollón has frequently been hit by large scale flooding events including ones during Hurricanes Fifi (1973), Mitch (1998), Stan (2005), Ida (2009), Tropical Storm Agatha (2010), and Tropical Depression 12-E (2011).

As a United States Peace Corps volunteer, I spent 2 years working as a Disaster Prevention and Mitigation specialist in El Borbollón. Living among the community, I had the unique opportunity of obtaining first-hand accounts and opinions from the local population about living with natural hazards. My time there overlapped with a severe meteorological event known as Tropical Depression 12-E. Near the end of the wet season (October/November) in 2011 this tropical cyclone dumped intense precipitation across all of Central America. According to the International Federation of Red Cross and Red Crescent Societies (IFRC, 2013), Tropical Depression 12-E nearly doubled El Salvador's regular annual rainfall amount, killing dozens of people and forcing nearly 60,000 people throughout the country to evacuate their homes. The community of El Borbollón was especially hard hit, as it sits at the base of a large water basin. I was a participant observer to the ways in which the community prepared for, responded to, and recovered from almost $5 \mathrm{~m}$ of flooding waters. This gave me unique insight into the ways in which the local and regional level governments, as well as non-governmental organizations (NGOs), responded to the disaster. 


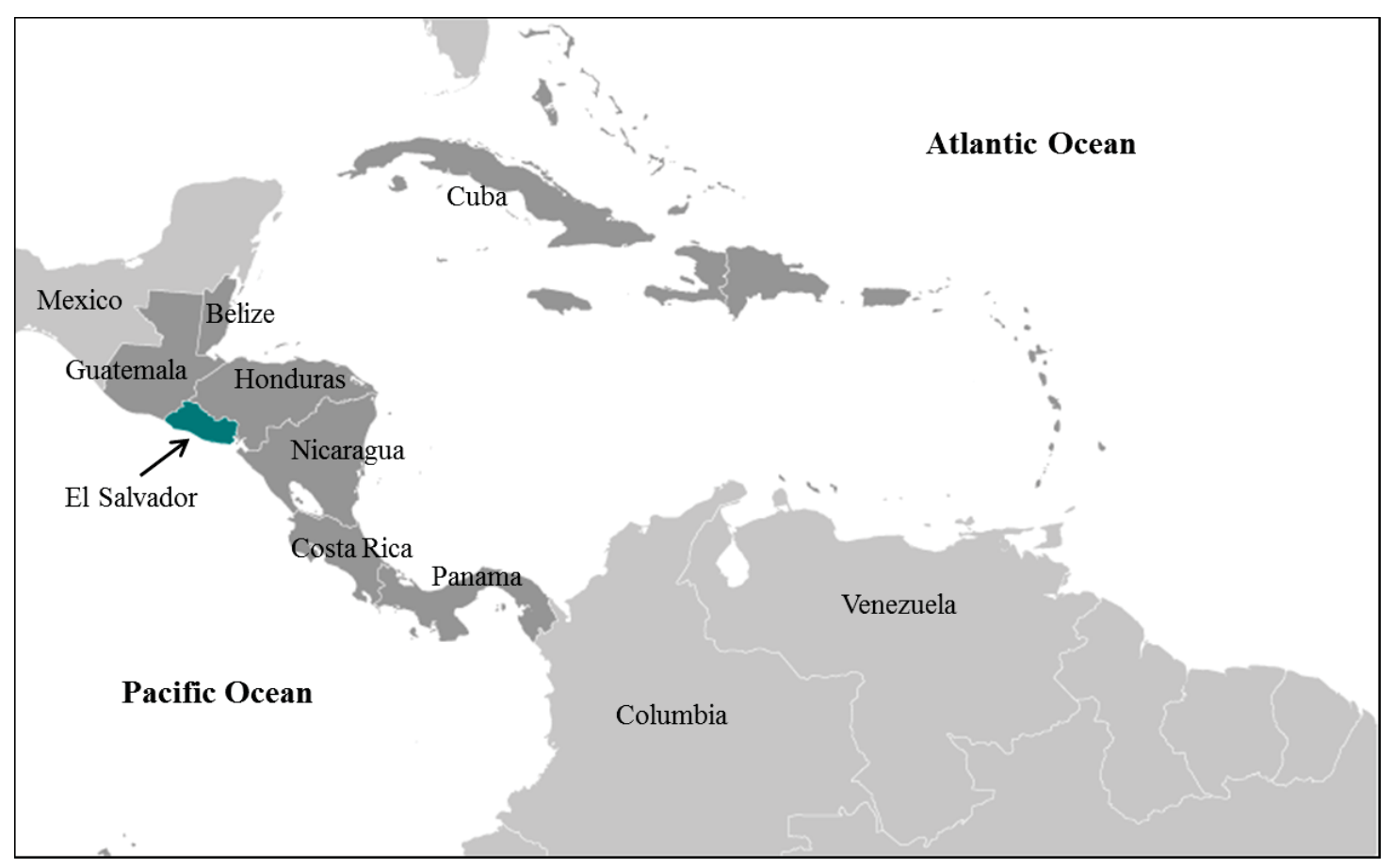

Figure 1: Map of El Salvador and Central America. Adapted from Central Intelligence Agency (CIA) (2014).

\section{Geographic and Geologic Setting}

El Salvador is located in Central America, between Guatemala and Honduras, bordering the Pacific Ocean (Figure 1), spanning an area of 21,041 square kilometers (roughly $200 \mathrm{~km}$ in length by $100 \mathrm{~km}$ in width). The country sits on a tectonically active subduction zone, making it extremely susceptible to volcanic eruptions, earthquakes, landslides, floods, and hurricanes.

The eastern region's landscape is dominated by the 2,130 m San Miguel stratovolcano, known locally as Chaparrastique. It is one of El Salvador's most active volcanoes, having experienced about 30 eruptions in the past 250 years, giving this volcano about $16 \%$ chance of an eruption occurring in a given year (Cartagena et al., 2004). The town of El Borbollón sits on the south flank of Chaparrastique, atop a 200 year old lava flow (Chesner et al., 2004), of which a large portion is exposed basaltic rocks (Figure 2 and Figure 3).

The southern tip of this lava flow borders the northern edge of a large, shallow, lagoon, locally referred to as Laguna El Jocotal. During the dry season, which typically spans from November to April, the lagoon encompasses roughly $8 \mathrm{~km}^{2}$ (Benitez et al., 1999), with an average depth between 0.5 and $1.5 \mathrm{~m}$. At this time, it sits at an elevation of $24 \mathrm{~m}$ above sea level (ASL). The wet season (or rainy season) extends between May and October, and often sees the lagoon swell up to $16 \mathrm{~km}^{2}$ (Benitez et al., 1999). This incredible increase in water comes partly from the local rains and mostly from the inflow of the river known as Rio Grande San Miguel. The 
entire basin seen in Figure 7 drains into the Rio Grande San Miguel and this river eventually enters the lagoon from the south-east, filling it with flood waters.

The area has a significant history of flooding, as each of the hurricanes and tropical storms mentioned above have brought multiple meters of flooding above dry season levels. Additionally, the Laguna El Jocotal and immediate surrounding region are covered by quaternary flood deposits (Renderos et al., 2013), and continue to be influenced by regular flooding events to the present day.

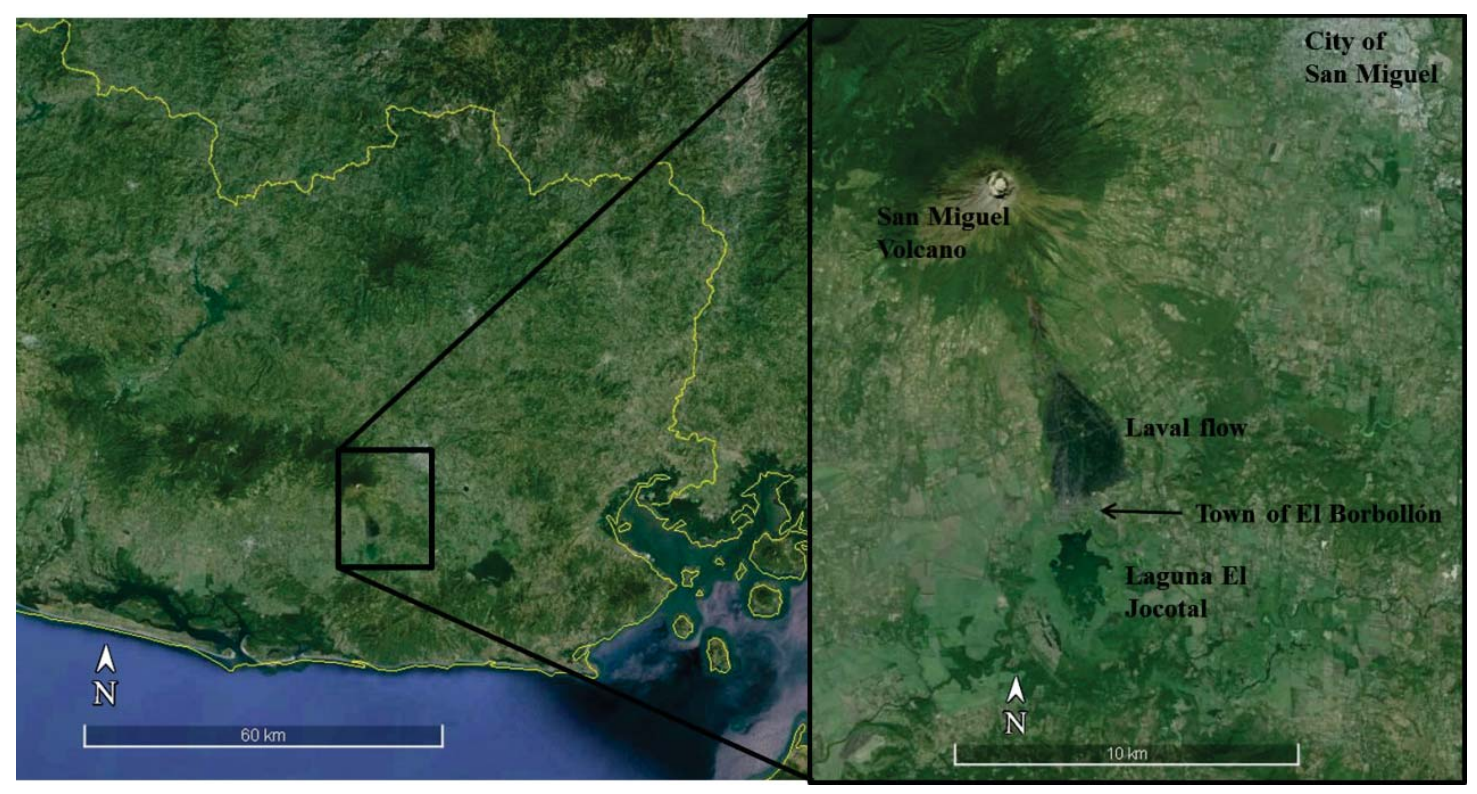

Figure 2: Satellite image of the eastern region of El Salvador. Inset is a closer view of the relative locations of San Miguel Volcano, El Borbollón, and the Laguna El Jocotal. Adapted from Google Earth Pro (2015a) (Map data: Google, CNES/Astrium, DigitalGlobe).

\section{Community Setting}

El Jocotal and the surrounding vegetation are a federally protected area, and part of an intergovernmental treaty convention on wetlands known as the Ramsar Convention (Ramsar.org, 2015). The Laguna El Jocotal is home to over 275 species of migratory and local birds, 150 different types of plants and 100 species of aquatic life (MARN, 2004). A vital sanctuary for freshwater and migrant bird species in the country, Laguna El Jocotal is also among its most disturbed by human activity (Komar, 2002). It is intensely fished, ranchers graze cattle at the water's edge, wooded areas are visited daily by those in search of firewood, and the protected areas are difficult to differentiate from privately owned and un-regulated territories. Park guards are understaffed and ill equipped to prevent poaching and looting of the lagoon's natural resources.

The human population around the lagoon is estimated at 3000 by the local Park Rangers, though no official census data exists. This number is commonly repeated when other community members are asked the same question. $86 \%$ of Salvadorans are 
'mestizo,' which means a mix of indigenous Native American and European Spanish origins (CIA, 2014), and with no improved data, we assume this proportion holds true within El Borbollón. The country's official language is Spanish, though some small clusters of native groups also speak their own language.

The densely populated area within the community is bisected by an east-west highway. The north half is slightly higher in elevation and predominantly built on top of exposed black basaltic rocks. The lower-lying southern region makes up the northern edge of the lagoon, and is therefore more lushly vegetated (Figure 3). A single school sits on the highway, and teaches both elementary and middle school levels to local children as well as those from surrounding communities. The school grounds are often the venue for many larger community events and meetings throughout the year.

Fishing plays a huge role in community life and contributes enormously to its economy and wellbeing. Many families sell their catches to passersby's along the highway. Others eat fish almost every day as it is a convenient local source of food, and "free," assuming the effort to catch them can be put forward. According to my observations, nearly every family has one or more members who fish daily. According to a Park Ranger, a study was done by a local NGO known as CENTAPESCA, which found that the lagoon can sustainably support 70 or 80 fishermen. Unfortunately, there are over 250 in the local fishermen's co-op alone, plus a number who fish illegally. Despite the strict guidelines, the lagoon is overexploited by these unsustainable practices.

Cash currency is used in the community, though a significant bartering system is also in place. Often this is in the form of fishermen trading fish for other types of food, such as corn or beans, but it can vary and encompass virtually any transaction, as we will see later.

Over one fifth of El Salvador's population lives abroad, mostly in the U.S., Canada, Mexico, and neighboring Central American countries. Remittances (money sent from those working abroad back home to their friends and family living in El Salvador) accounts for nearly $20 \%$ of the country's GDP, comprising one of the largest sources of income for much of the country's population (CIA, 2014). This is also true of El Borbollón. Many receive monthly money transfers, and use this as a primary source of income.

Apart from fishing and remittances, the most common form of income within the community makes use of the pervasive volcanic rocks from the exposed lava flow seen in Figure 3. Laborers use sledgehammers and pick-axes and break these up in place, load them into vehicles, and then sell them by the truckload throughout the region, mostly for use in construction projects.

The community of El Borbollón is divided in terms of religion. No congregation follower numbers exist, but I have seen at least 5 churches within the community; the largest being Roman Catholic, and Protestant. There is, however, a large contingent of followers of the Evangelical faith within the community.

Rapid expansion of the natural-resource based community in the past 30 years coupled with poor water management practices has put pressure on the local hydrological system. Residents depend on the lagoon for their wet and dry season 
water supply. Community water well pumps run for only half the day to avoid over pumping, and locals regularly use chemical soaps and detergents when washing clothes and dishes at the water's edge.

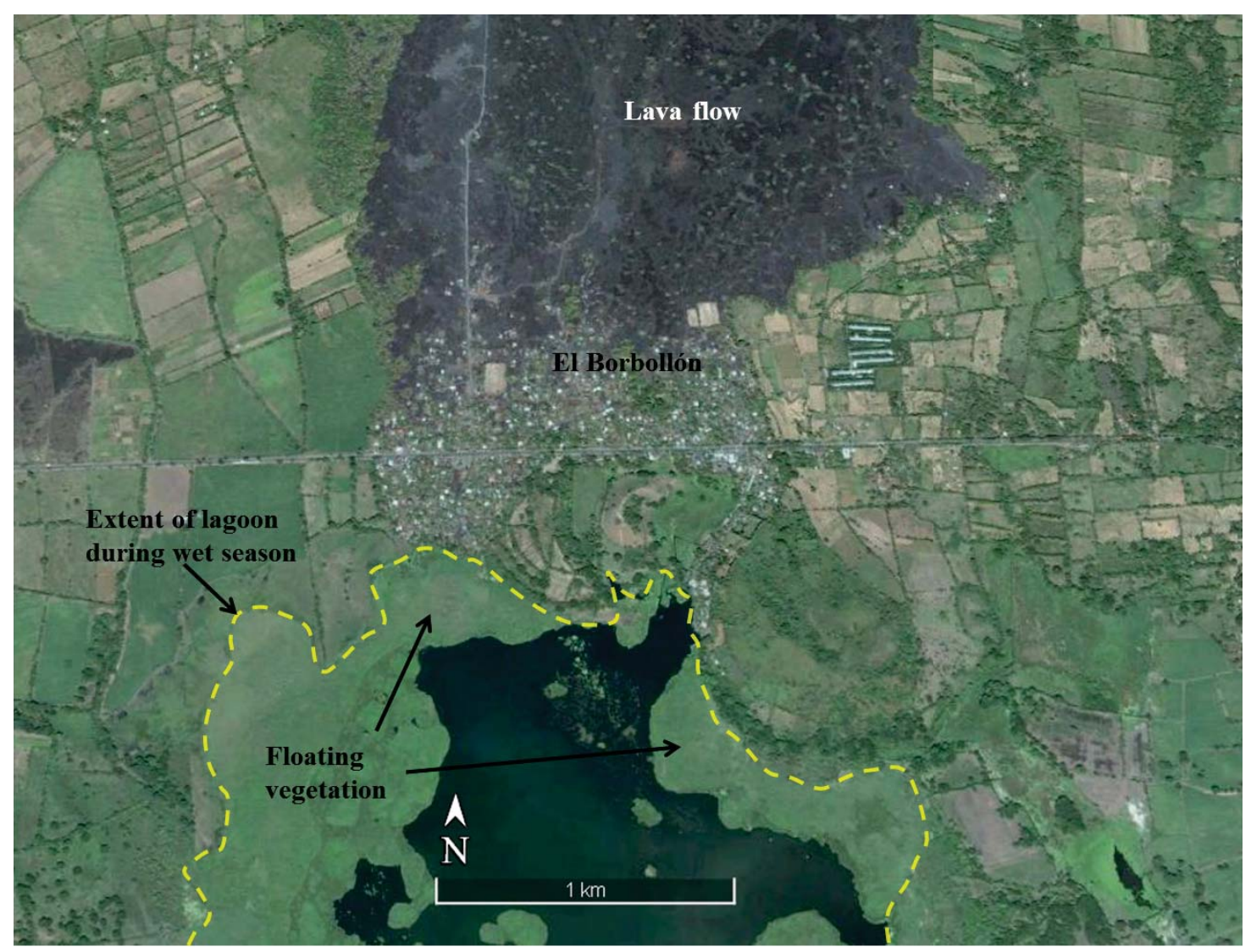

Figure 3: Detailed satellite image of community of El Borbollón, along with the southern tip of a lava flow and the northern edge of Laguna El Jocotal. Image taken during dry season (April). Adapted from Google Earth Pro (2015b) (Map data: Google, CNES/Astrium, DigitalGlobe).

\section{Goals of the research}

The combination of hydrological and social sciences at once broadens the usefulness of the model as well as specifies its potential audiences. This project evaluates both the hydrological as well as the social aspect through two different, but complementary angles. This parallel case study research is then brought together and contemplated.

The objectives of this research are to:

1) Combine computer modeling and remote sensing techniques to provide an improved assessment of the flood hazard; 
2) Validate the model for use in a new area with limited data by comparing the modeled outcome against an event of known parameters;

3) Examine the role that large scale flooding events (change in depth of $4+$ meters from dry season levels) play in the lives of local community members; and

4) Estimate the value that broadening the concept of a hydrological model to include social data brings to the case studied here, as well as defining its utility for different audiences with different purposes.

\section{Methods}

Parallel research efforts between hydrological and social sciences were conducted, as shown in Figure 4. First, a common approach to flood hazard assessment using hydrological modeling was conducted using a computer simulation coupled with GIS visualization. This computer model was then validated by using remote sensing as an independent means of evaluating the floods from our case study. Second, an analysis of the community's attitude and vulnerability towards flooding was conducted using results from a survey, interviews, and participant observation. Ultimately, the worth of the computer modeling was discussed from the point of view of the community, as well as its potential helpfulness to other audiences.

There are many computer programs available to simulate the hydrologic processes of watershed systems. I chose the Hydrologic Engineering Center's Hydrologic Modeling System (HEC-HMS), a free modeling software package created by the U.S. Army Corps of Engineers that is designed to simulate precipitation-runoff events. It translates excess rainfall into overland flow and runoff and was chosen in part because of its ability to show how a given basin responds to a single rain fall event. A number of studies have shown that the HEC-HMS hydrologic modeling has proven useful in flood forecasting in a wide range of locations (Knebl et al., 2005; Anderson et al., 2002; Oleybiblo \& Li, 2010; Chu \& Steinman, 2009), but not much work has been published using HEC-HMS in areas with very limited data.

Digital elevation models (DEMs) were obtained from NASA's Reverb website (http://reverb.echo.nasa.gov/) and processed using a geographic information systems computer program (ArcGIS). DEMs are used with increasing frequency in automated stream network and watershed delineation (Saunders, 1999), due to their reliability and reproducibility. An extension within ArcGIS, "HEC-GeoHMS", was used for terrain and basin preprocessing, creating the input files necessary for the HEC-HMS simulation program itself. Additionally, using the 3D Analyst Tools in ArcGIS, flood plains of varying depths were created and used to generate graphs of the relationship between the depth of the lagoon versus the flooded area, and depth of the lagoon versus volume of flooded water.

HEC-HMS was run using historical rainfall data provide by SNET (2015), which spans the years of 2011 and 2012, in order to provide a flood evaluation for the zone. Using a program called HEC-DSSVue, the precipitation data was formatted for use within the HEC-HMS simulation. The location of the rain gauge can be seen in Figure 7. Specifically, the latter weeks of October 2011 were analyzed in some detail. This time frame coincides with the end of the 2011 Pacific hurricane season, during 
which the very large rainfall event known as Tropical Depression 12-E affected the entire country. During this event, the water level at Laguna El Jocotal raised by $4.9 \mathrm{~m}$.

The results of the HEC-HMS simulation using precipitation data from Tropical Depression 12-E were validated by comparison with historical ASTER satellite imagery to map the extent of the 12-E flood levels. ASTER is often used in remote sensing studies of flood delineation (Tralli et al., 2005). Satellite imagery is also useful for studying watersheds as it can cover large areas. ASTER has the spatial and temporal resolution required for regional modeling purposes. Using the program Erdas Imagine, ASTER bands were converted from Digital Numbers into radiance and spatially projected. A composite file with Bands 3, 2, and 1 (near-infrared, visible red, and visible green, respectively) was created for the analysis. These bands were chosen because of the absorption properties their respective wavelengths $(0.76-0.86 \mu \mathrm{m}$, $0.63-0.69 \mu \mathrm{m}$, and $0.52-0.6 \mu \mathrm{m})$ have for water, making them convenient for water delineation. For better visualization, all images were stretched between 0.75 to 1.75 standard deviations.

People have widely varying reactions to dangerous scenarios (Fritz \& Marks, 1954), and behavioral data is not often taken into account in hazard planning based on hydrological models. An oft used method to relate social data to natural hazards is the Disaster Risk Index, created by the United Nations Development Programme (UNDP). Its goal is to model human vulnerability by taking into account various types of disasters and overlaying it with population distribution and other socio-economic information (Peduzzi et al., 2009). Another example of social sciences increasing overall knowledge of a community's reaction to a disaster is the recognized biasing effects of memory and imagination of past experiences and events, which could negatively affect an objective discussion of risk (Barnes, 1984). Another example of how people affected by disasters may not act in the expected manner could be the statistically higher refusal to evacuate among people with pets (Heath et al., 2001), who accept a higher level of risk by staying with their domesticated and livestock animals. Due to its proven utility, an analysis of the community's attitude towards flooding events was conducted.

The analysis included a preliminary survey with 19 random households within the community. Participants were a mix of both men and women, roughly aged between 20 and 70 years of age. A combination of close-ended, matrix style, and open-ended questions were asked (see Appendix 3) in a face to face setting, and the answers were written down by the interviewer. This tool was used within the first 10 months of my time in the community, allowing (1) time to familiarize myself with the local language, (2) time for the community to feel more comfortable speaking with me, and (3) allowing me to better orient myself in the field. Interesting themes within the community's perspective on recurrent floods were drawn out and expanded on with 3 one-on-one interviews, and a single-group interview. These digitally recorded interviews, conducted almost 2 years after arriving and living in the community, are all 1 to 1.5 hours in length, and targeted key members of the community including: three official Park Rangers (tasked by the federal government with patrolling the lagoon and surrounded shoreline to prevent poaching, illegal deforestation, and overfishing, as well as helping ecosystem conservation efforts), one local member of 
the government's Civil Protection agency (tasked with preparing for and responding to all natural disasters), one resident landowner and farmer who lives at the lagoon's edge, and one community leader who is a retired Park Ranger and has lived both within and outside of the flooding reaches. All interviewees were middle aged to elderly men, who had spent their entire lives living in the community, and were chosen because of their familiarity with the community and its hydrological history, as well as potential relevance to my research.

Status as a participant observer for 24 months provided much insight into how the locals have adapted to almost regular extreme flooding cycles. This immersion into the community gave me a deeper understanding of the details and complexities surrounding the situation. Much less information could have been obtained solely through the use of surveys or literature (as none exists for the subject matter / area). Field notes were taken and referred to regularly, especially over the time span of Tropical Depression 12-E. This proved vital information, as there was a stark difference between what many residents said and what they actually did.

Asides from collecting ethnographic data on floods as a participant observer, my work as a Peace Corps volunteer focused more generally on the topic of Disaster Prevention and Mitigation (DPM). This included work such has hosting and running DPM workshops for local officials, creating evacuation routes in businesses and schools throughout eastern El Salvador, running earthquake drills in multiple local schools, being a part of geophysics surveys aimed at constraining lahar and landslide risks, Global Positioning System (GPS) campaigns measuring geo-deformation along active volcanic slopes, helping with the regular volcanic monitoring of the region, and the creation of a step-by-step manual for inexperienced locals to prepare and train others in DPM strategies covering a variety of hazard types. Additionally, my side project work in the protection of biodiversity with the Park Rangers and the fishermen's co-op provided important insights into the community's views on the lagoon. My work on environmental education for all ages allowed me to identify the gaps of information and knowledge vis-à-vis the lagoon. Even though not all of this is related to floods, it exposed me to information that was important to understanding the community response to flooding.

Very few official documents regarding hazard response from the national or local government were made available to me. Through my work with the school, I had access to the Ministry of Education's "School Protection Plan," which outlines preparatory steps as well as actions to be taken during a natural disaster or any other sort of emergency. The ways in which this booklet was organized and presented offered insight into the federal government's aims at a planned, coordinated, and uniform response to disasters.

Using the methods described above, we will first look at the hydrological analysis and its findings, before delving into the social analysis, and then a discussion of how these subject matters interact. 


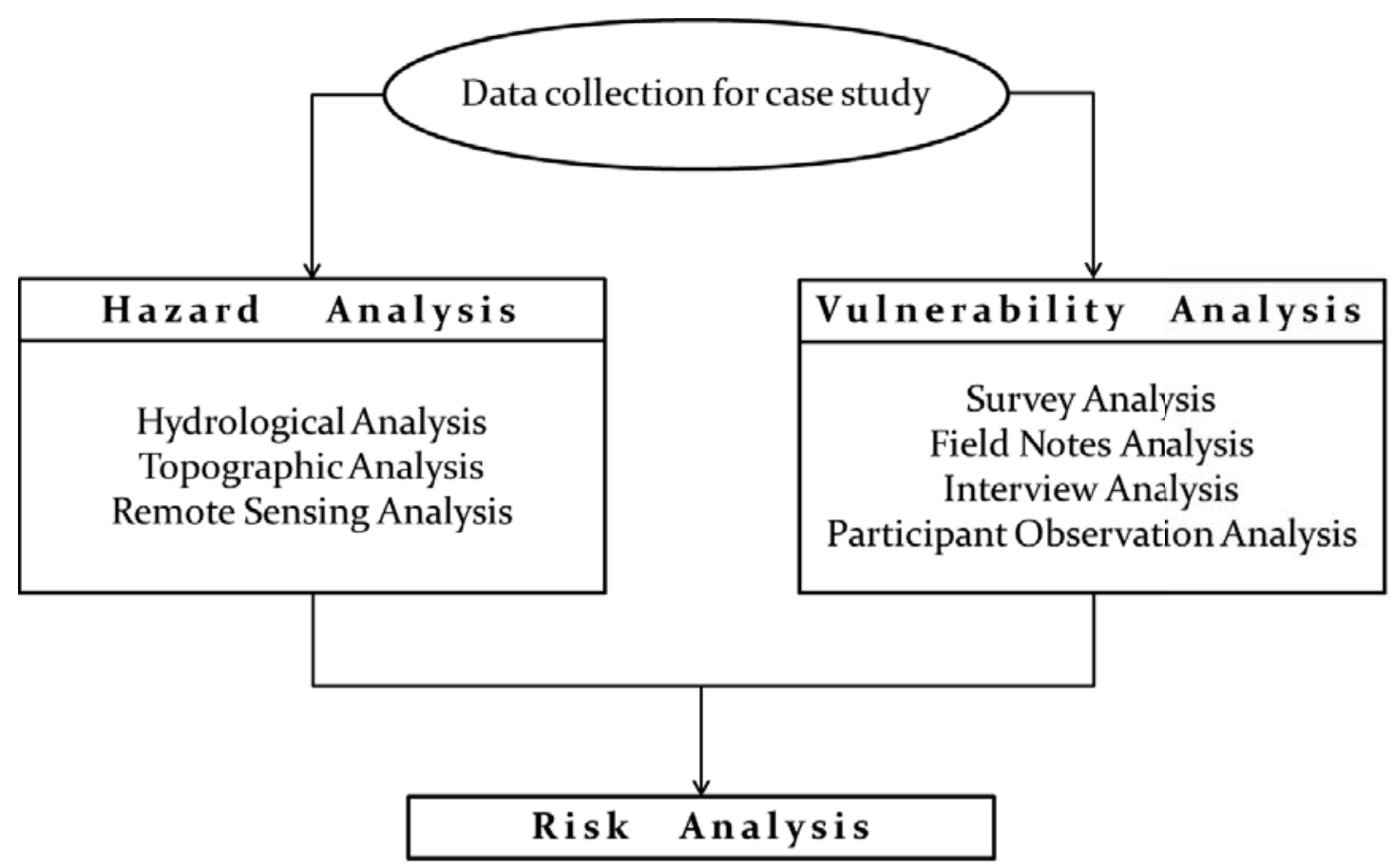

Figure 4. Methodology flow chart showing analyses undertaken during parallel hydrological (hazard) and social (vulnerability) researches.

\section{Hydrological analysis results}

An overview of the workflow for the Hydrological Analysis section can be seen in Figure 5. The individual components are described in detail in the following subsections. 


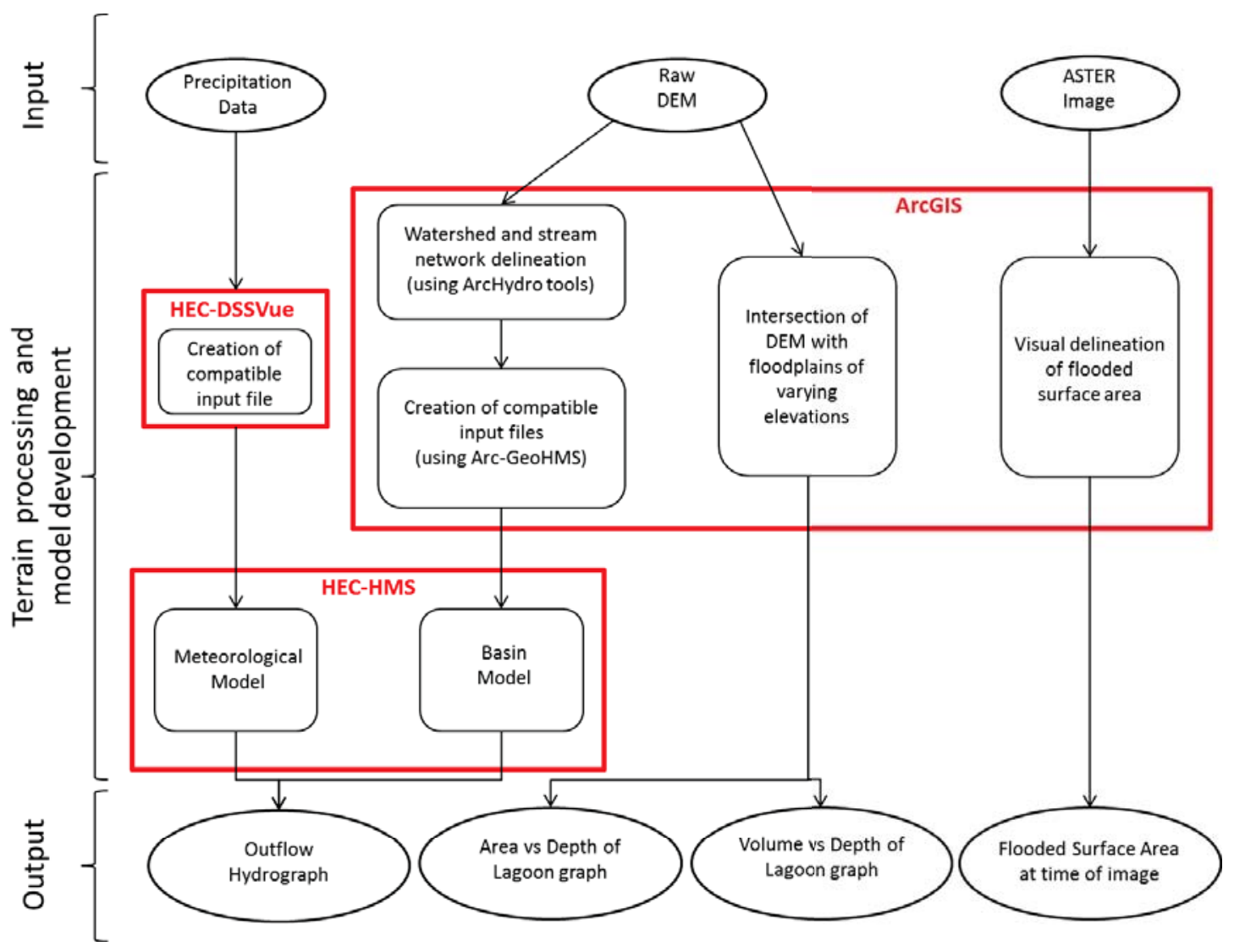

Figure 5. Hydrological Analysis workflow, where 'Input' is the original data used, and 'Outflow' describes what has been produced. Each red box represents the work done within a particular computer program.

\section{HEC-HMS simulation}

HEC-HMS requires many parameters, equations, and values to be defined by the user. Because of the lack of data in the study area, the model cannot be as accurately delineated as an area that has many data points to constrain the model. The simulation's settings were left in the default mode, unless otherwise stated here. Calibrating the model was done by trial and error. The hydrologist usually makes a subjective adjustment of parameter values to incrementally improve the fit between the observed and simulated hydrographs. As there is no local hydrograph data to use for calibration with the computer model, field notes, local accounts, and personal observations were used in place of actual recordings when selecting and adjusting values. The methods used include the ability of soil to absorb rainfall (the loss rate method), the transformation of rainfall to runoff (the transform method), the filling of streams with previously infiltrated water (the baseflow method), and the path taken by water in streams (the routing method); these are all discussed in the following paragraphs. 
A flowchart of the necessary inputs, chosen methods, and required parameters used for the model creation in HEC-HMS are depicted in Figure 6. A complete list of method options is provided in Appendix 1.

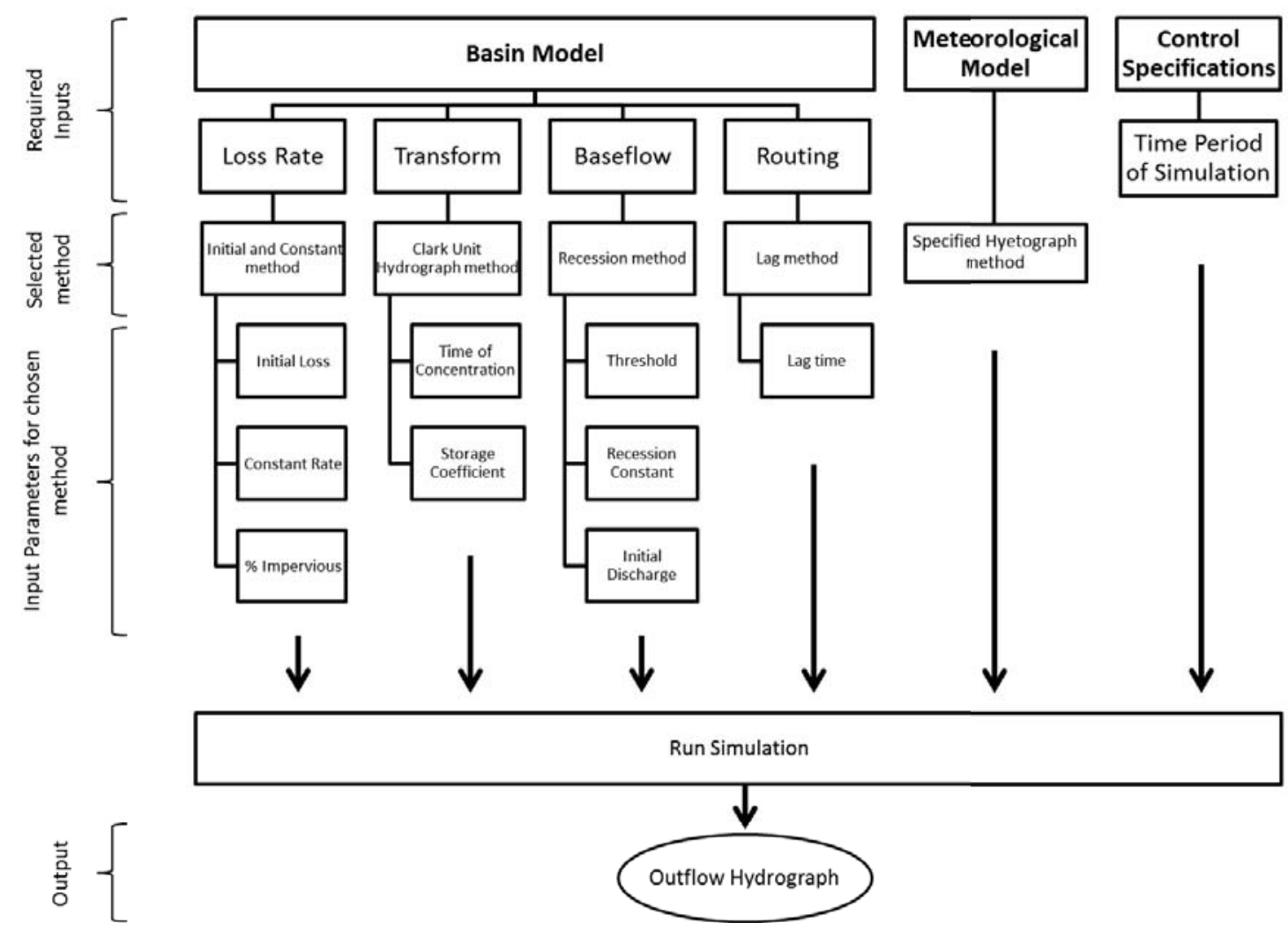

Figure 6. Work flow within the HEC-HMS program.

The loss-rate method options in HEC-HMS define the equations used in the simulation to compute volume losses from rainfall, also known as runoff-volume. In this study, the 'Initial and Constant Loss Method' was chosen. It assumes that all rainfall is lost until the volume of "initial loss" in satisfied, and then rainfall is lost at a constant rate. This is intended to mimic the ability of soil to absorb a limited amount of rainfall before becoming saturated and allowing a certain amount of surface flow. It is best for our situation because of its simplicity and functionality with watersheds that lack detailed soil information (USACE-HEC, 2010). 'Initial Loss' defines the initial basin condition, defining the amount of rainfall that can be absorbed by the soil, in millimeters; if the basin is saturated, this value will approach zero. The value used in the model for this parameter was zero $(0 \mathrm{~mm})$, as Tropical Depression $12-\mathrm{E}$ occurred near the end of the wet season, when the soils had already been exposed to months of rains and were likely completely or nearly saturated. The 'Constant Rate' loss parameter, in millimeters per hour $(\mathrm{mm} / \mathrm{hr})$, represents the maximum infiltration capacity of the soils (USACE-HEC, 2000). This value was chosen to be $5 \mathrm{~mm} /$ hour, 
based from a table of infiltration capacity values for a variety of soil types (Akan, 1993), which is presented in Appendix 2. The Loss method parameter is the areal percentage of the sub-basin that is impervious to rainfall, such as urban sprawl, road cover, and other concrete-covered surfaces, and was estimated at 5\% based on satellite imagery using Google Earth.

The transform method options dictate how excess rainfall is transformed into direct runoff. USACE-HEC (2000) provides guidelines for choosing an appropriate method, based mostly on availability of information. The 'Clark Unit Hydrograph' option was chosen, as it is considered the best method to model direct runoff from individual storm events, does not require detailed knowledge of the spatial runoff distribution, and takes into account irregularly shaped watersheds (Sabol, 1988). The two parameters necessary for this method are 'Time of Concentration' (in hours), and 'Storage Coefficient' (in hours). The time of concentration is the time it takes water to travel from the (hydraulically) furthest point in the sub-basin to the outlet. The storage coefficient defines water detention effects within the sub-basin such as ponds, lakes, and ephemeral features (Sabol, 1988). The Time of Concentration used for this study was 24 hours, and for Storage Coefficient, 12 hours, based on repeated field observations and discussions with residents about historical rainfall and streamflow activities.

The baseflow method options are used to estimate the return of infiltrated precipitation back into the stream flow during a rainfall event. The 'Recession Method' was chosen. It is more applicable to shorter duration periods and watersheds where volume and timing of the baseflow are strongly influenced by precipitation (USACE-HEC, 2000), which is the case for this study. Parameters for this method include 'Initial Discharge,' 'Recession Constant,' and 'Threshold.' The initial discharge is the baseflow at the beginning of the simulation, expressed in cubic meters per second. This value was set to zero, as no major rivers or streams enter into the subbasin, and all flow is directly related to precipitation. The recession constant dictates the rate of baseflow decay between storm events, and is of "less importance" as only one storm was modeled in this study, according to a USGS report (Westerman and Clark, 2013). It is defined as the ratio of baseflow at the current time, to the baseflow one day earlier, and is used when the channel flow recedes exponentially after an event (USACE-HEC, 2010). Hence, the values are between 0 and 1 . In this study, the recession constant used was 0.9 , and represents an estimate based on personal observation and discussions with local residents. The threshold is the point where baseflow replaces overland flow as the source of flow from the sub-basin (Peters, 1998), and a 'Ratio to Peak' setting was chosen with a value of 0.25 , meaning that the value of baseflow is reset when the current flow divided by the peak flow falls below 0.25 . This value was chosen because it is an average value used in similar work dealing with tropical wetlands such as Moliere (2002), and large scale precipitationflood events such as Cho (2014).

The routing method option in HEC-HMS is used for calculating travel time of channel flow values throughout the sub-basin. The 'Lag Method' was chosen. It requires the fewest inputs, as it simply offsets the hydrograph without any attenuation (USACE-HEC, 2010). The lag values chosen across the different reaches of the sub- 
basins varied, with the assumed overall travel time through the upper and central subbasin estimated at 24 hours total, and the travel time through the lower sub-basin to be valued at 7 days (168 hours). These values are based on field notes, local accounts, and personal observations. 


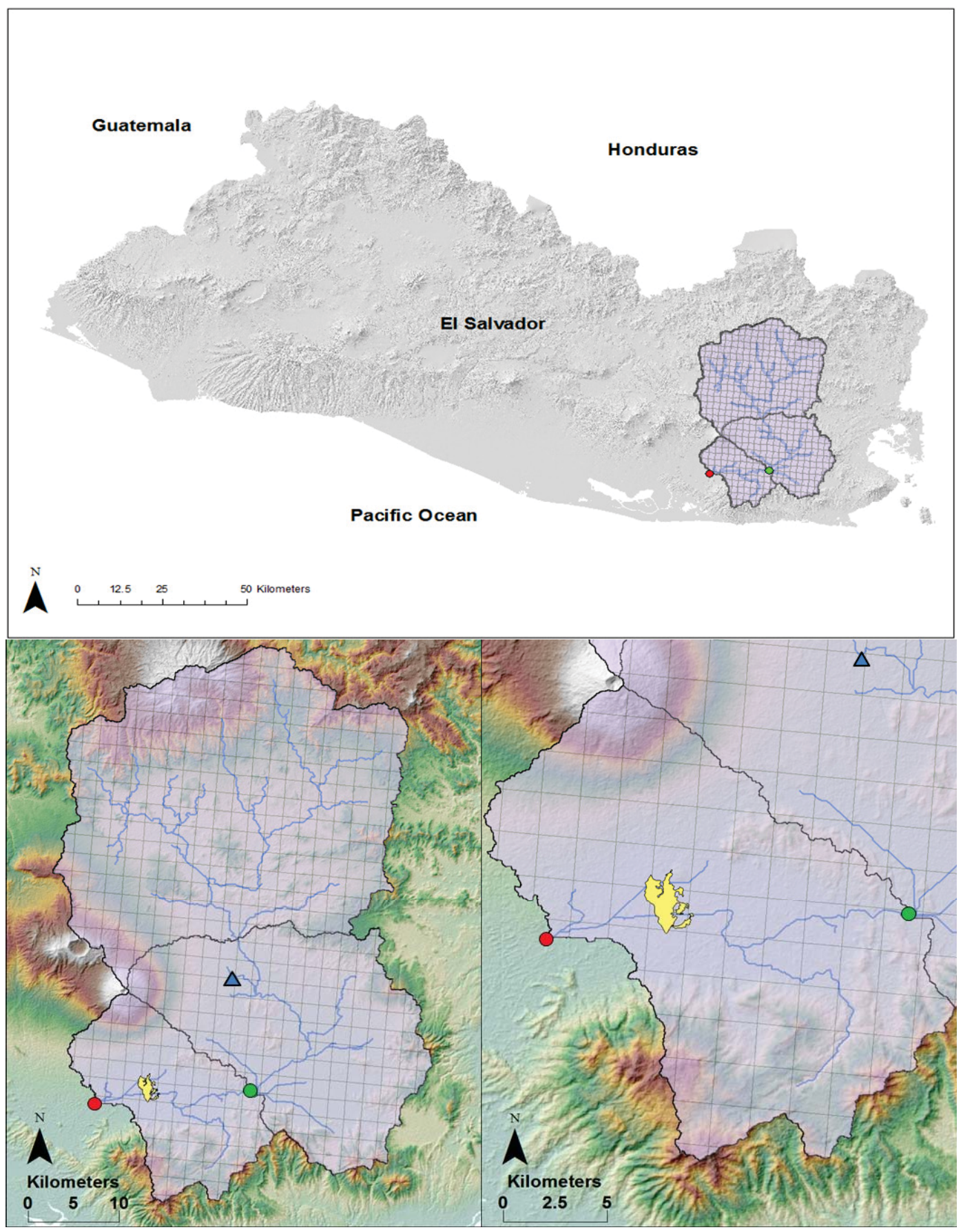

Figure 7: Location and extent of basin analyzed in HEC-HMS. Yellow shape is outline of Laguna El Jocotal during the dry season. The blue triangle is the location of the rain gauge. The Inflow point (represented by the green dot) represents the location where flow into the lower subasin was measured, and the Outlfow point (red dot) represents the location of where flow out of the subbasin was measured. 
The study area is mapped in Figure 7. The basin is divided into 3 sub-basins, referred to as the "upper," "central," and "lower" sub-basins, from highest to lowest (also north to south), respectively. The basin represents the catchment area in which any precipitation that falls within it will eventually make its way to the outlet (Outflow point) in Figure 7, and continue to the southwest, evenutally flowing into the Pacific Ocean. The catchment area was delineated automatically using ArcGIS, whereas the Inflow point was chosen based on a topographically-driven funneling of the stream network, which focuses all surface water flow through a single point, allowing for a more accurate reading of model results. Almost all of this precipitaction will flow through the Laguna El Jocotal. This study basin extends from the northern Sierra Madre mountain range, across a central plateau, as far south as the Jucuarán mountain range (roughly $80 \mathrm{~km}$ by $40 \mathrm{~km}$ ). The elevation within the basin varies from near sea level to about $2000 \mathrm{~m}$ above sea level (ASL), with tropical climate temperatures correlating inversely with elevation.

In addition to the settings described previously, a HEC-HMS project includes a basin model, a meteorological model, and certain control specifications. The basin model is simply the DEM created in HEC-GeoHMS. Daily precipitation data obtained from SNET was imported into the program to create the precipitation model, using the 'Specified Hyetograph' method. This method was chosen as it is most useful for externally processed data and for instances when a single precipitation gauge is used to represent the entire basin (USACE-HEC, 2010). The control specification model determines the time period for the simulation and, in this study, covers the duration of the Tropical Depression 12-E event. It ignores the effects of later rainfall events on the flooded lagoon, which likely affect the tail end of the event.

The final simulation produced flow rates at both the hydrological entrance and exit to the lower sub-basin, shown in Figure 8. It displays water flow over time into the lower sub-basin (inflow) and out of the lower sub-basin (outflow). When the green inflow curve lies above the red outflow curve, the lagoon is gaining water volume, and the water level is rising. When the outflow curve lies above the inflow curve, the lagoon is losing water volume, and the water level is dropping. At the point where they cross, on October 20, 2011, the lagoon is at its highest net volume and water level. This represents peak flooding level for the rainfall event. 


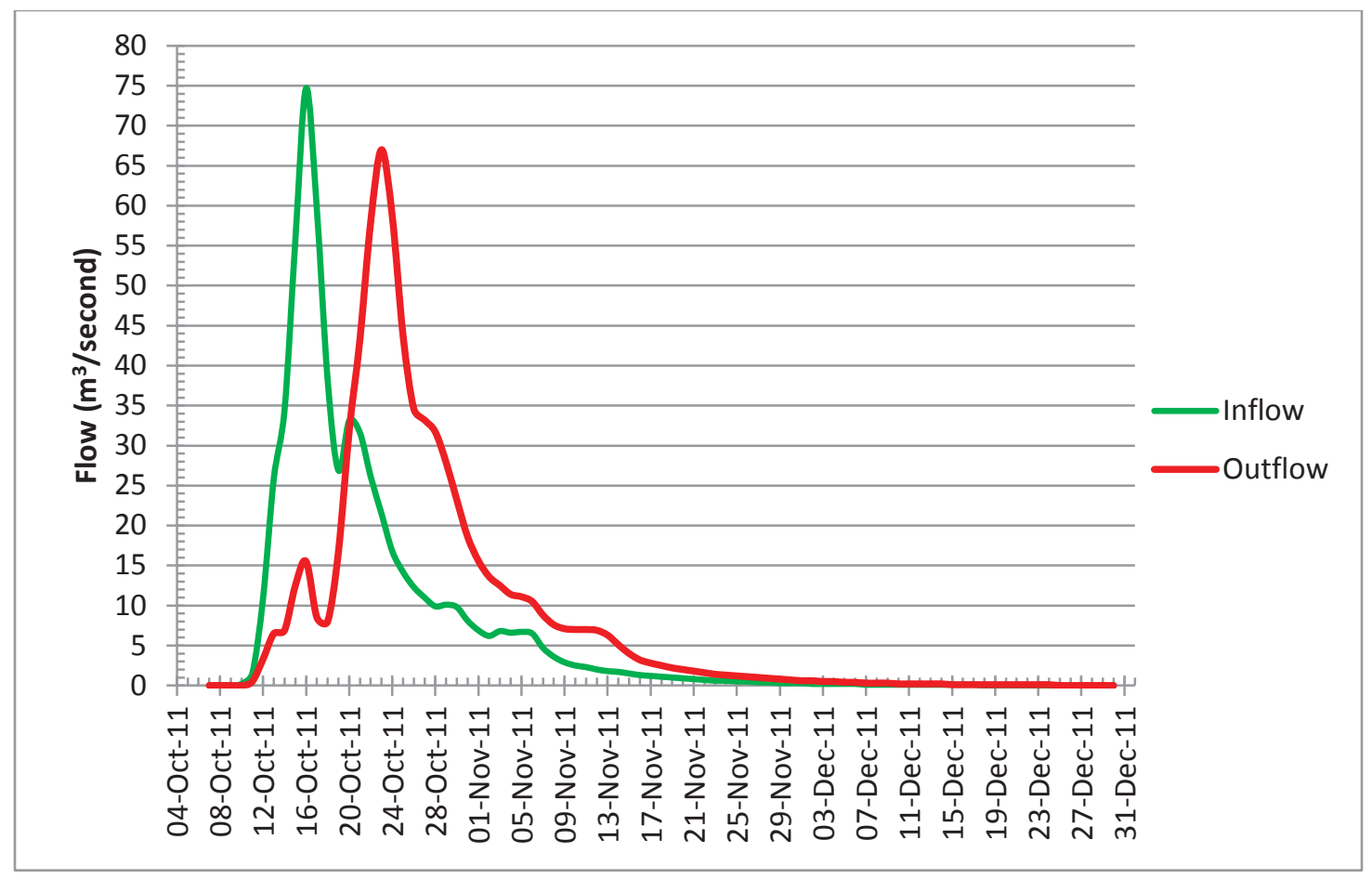

Figure 8. Modeled flow, in $\mathrm{m}^{3} / \mathrm{s}$, spanning the meteorological event Tropical Depression 12-E, as it enters and exits the lower sub-basin over time.

By integrating the inflow curve between the start of rainfall on October 7 and at the highest net volume on October 20 (finding the area beneath the curve between those two dates), the volume of water that entered the lagoon (via the Inflow point in Figure 7) in that time period can be calculated. Similarly, volume of water to have left the lagoon over the same time period is calculated by integrating the outflow curve.

To integrate the complex inflow and outflow curves, which have no analytical expression, the data was exported into a spreadsheet, where the curves were broken into very small segments and the trapezoidal rule used to approximate the definite integral (Eq. 1), using 127 time periods of 12 hours each (spanning 63.5 days), where $a$ and $b$ represent the starting and ending times of each increment.

$$
\int_{a}^{b} f(x) d x \approx(b-a) \frac{f(a)+f(b)}{2} \quad \text { Eq. } 1
$$

Integration of the inflow curve from October 7 to October 20, 2011, yields a volume of $29.8 \times 10^{6} \mathrm{~m}^{3}$ of water. Integrating the outflow curve over the same time span provides a volume of $8.2 \times 10^{6} \mathrm{~m}^{3}$. The difference is the maximum net volume of water that was stored in the Lower sub-basin on October 20 resulting from the precipitation of Tropical Depression 12-E. The difference, $21.6 \times 10^{6} \mathrm{~m}^{3}$, represents excess water beyond that stored in the lagoon during a normal dry season. 
The integration of the entire inflow curve gives us the cumulative amount of water that has entered the Lower sub-basin. The Lower sub-basin input location is shown as the green dot in Figure 7. The integration of the entire outflow curve tells us how much water leaves the Lower sub-basin at the discharge point shown as the red dot in Figure 7. The difference between these two curves tells us the net volume of water that was temporarily stored in the Lower sub-basin. The time history of the cumulative volumes, as well as net difference, is represented graphically in Figure 9.

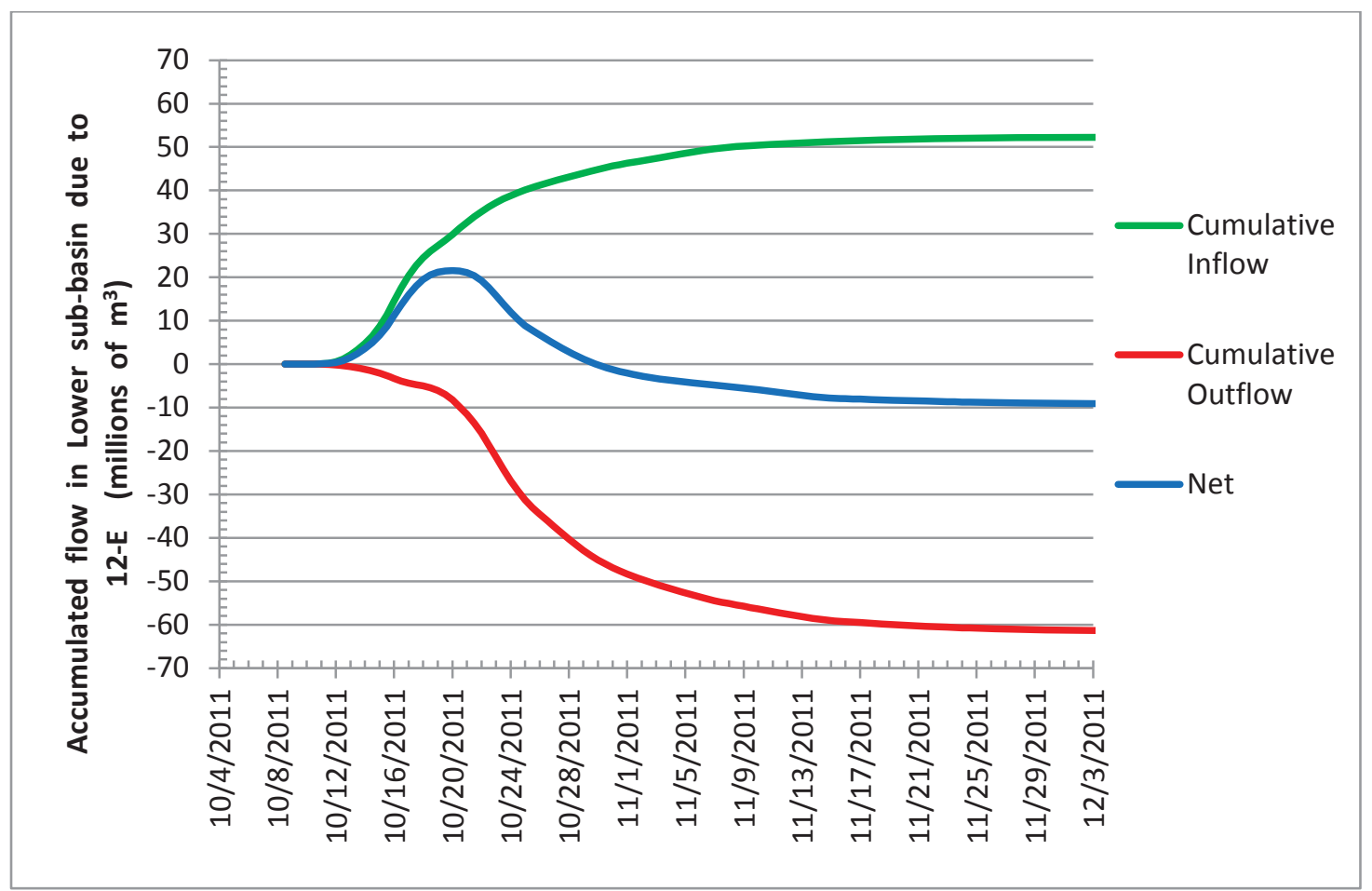

Figure 9. Cumulative Inflow volume, cumulative Outflow volume, and Net volume (Inflow minus Outflow) of water in the Lower sub-basin on a given day, due to precipitation from Tropical Depression 12-E.

It should be noted that the tail of the net volume of water curve in Figure 9 indicates negative values nearing the end of the meteorological event. According to the inflow and outflow hydrographs produced by the model (Figure 8), more water leaves the Lower sub-basin than enters it via the stream channel network. That is, the meteorological event left the sub-basin with a $\sim 9 \times 10^{6} \mathrm{~m}^{3}$ deficit in water volume. This is obviously not the case, and the discrepancy is likely due to the difference in precipitation between the inlet and outlet of the Lower sub-basin. The rainfall-runoff from both Upper and Central sub-basins flows into the Lower sub-basin, whereas the rainfall-runoff from all three Upper, Central, and Lower sub-basins flows out. 
Having examined the net inflow and outflow, the next step is to model the distribution of water in the lagoon over time, determining the spatial extent of flooding.

\section{Model simulations of parameter sensitivity}

In order to map the extent of flooding, various potential flood plains (with differing elevations) were created using the DEM (in ArcGIS). Figure 10 shows the raw DEM that was used in the lower sub-basin, including a detailed view of the lagoon. As the net water flow (from Figure 9) changes, we can use the DEM to determine the lateral extent and depth of flooding as predicted by the model. Figure 11 shows the relation between the lagoon's surface area and depth of water, and Figure 12 shows the corresponding relation between the volume of flooding water and depth of the lagoon. Data points to be discussed in the following paragraphs are also shown in these figures.

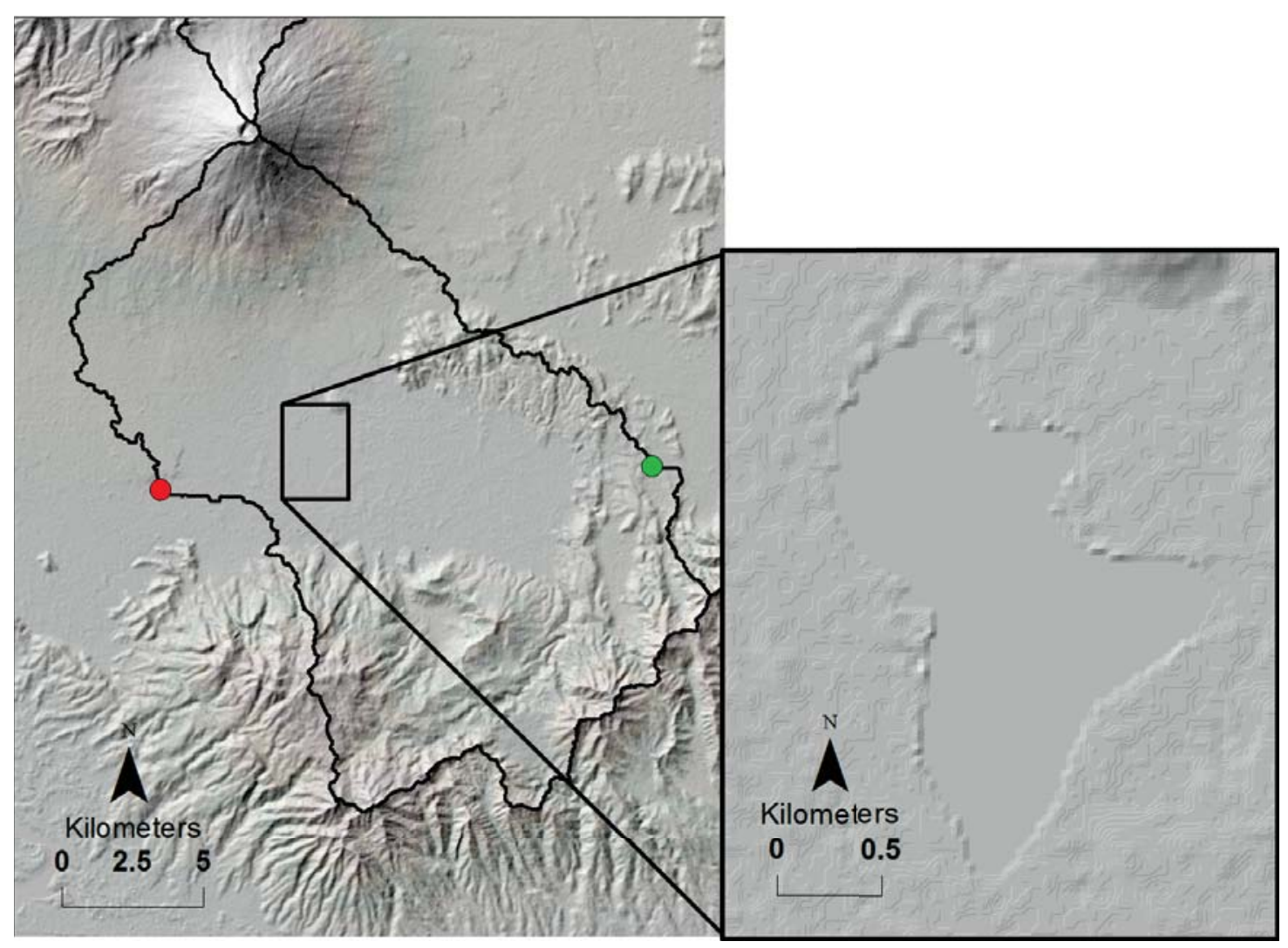

Figure 10. Detail of DEM in the lower sub-basin, used to compare flood plains to elevation surface. The flat surface of the lagoon sits at $24 \mathrm{~m}$ ASL. 


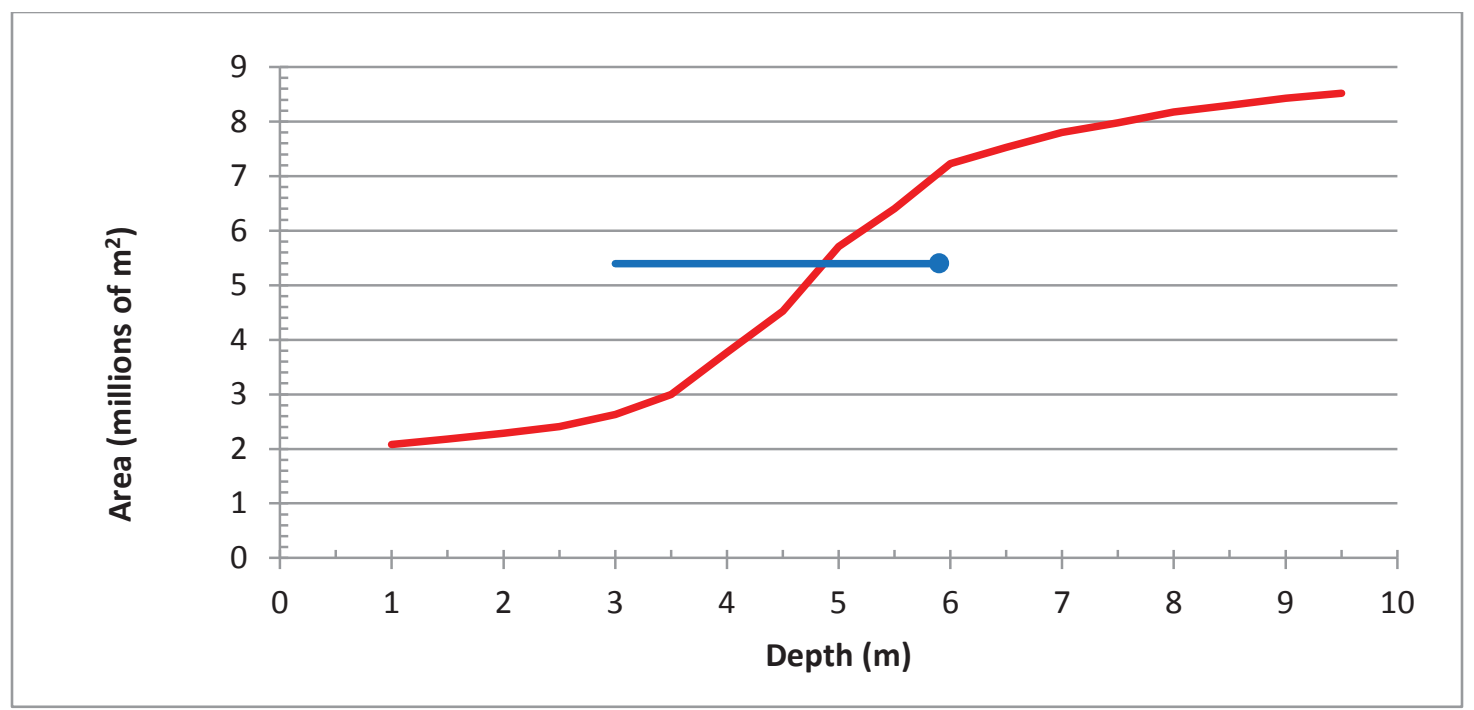

Figure 11. DEM-derived relationship between surface area and depth of the lagoon. The blue dot represents the maximum ASTER image-derived data point, and the blue horizontal line represents a range of possible values. The data from depth $0 \mathrm{~m}(23 \mathrm{~m}$ ASL) to $1 \mathrm{~m}$ on the red curve was omitted due to DEM artifacts.

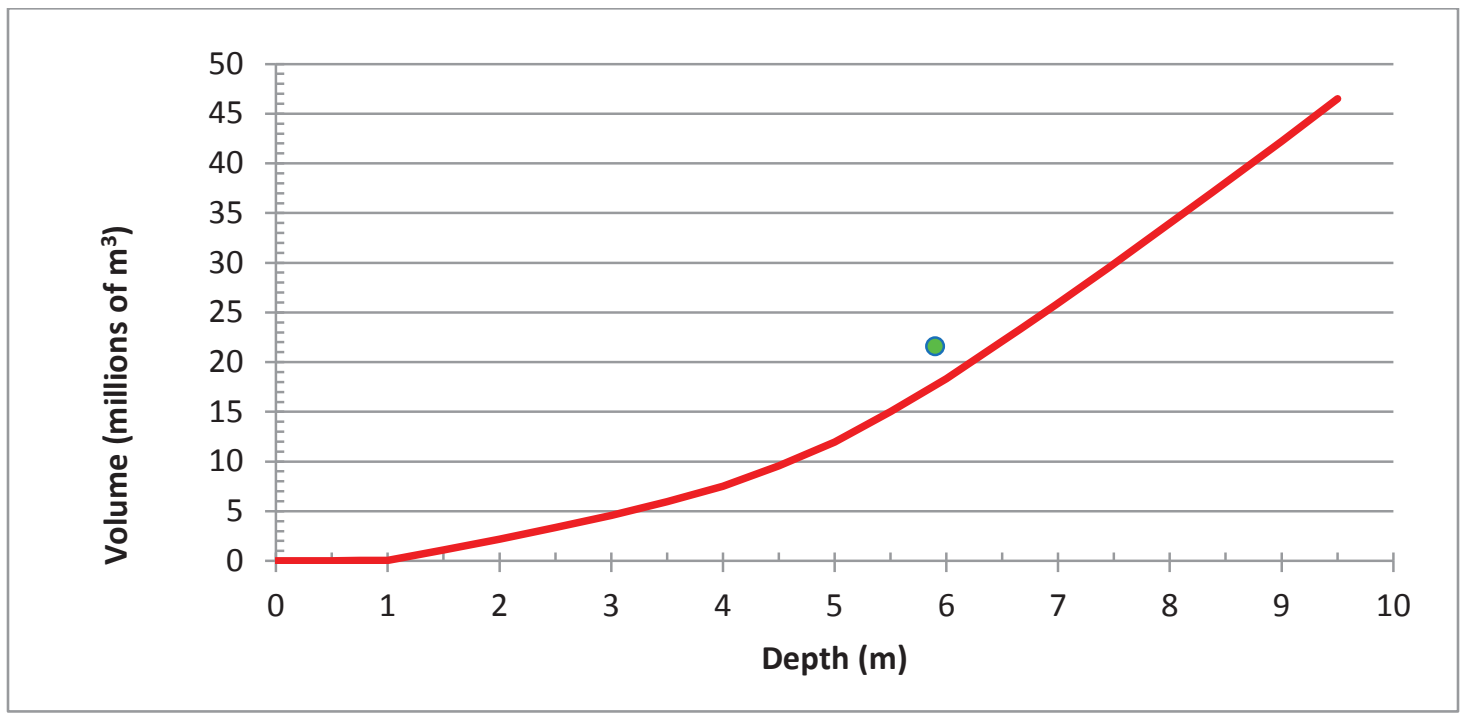

Figure 12. Volumetric increase in the lagoon waters as it relates to depth. This graph is based on DEM topography. The green dot represents the HEC-HMS produced data point.

For Tropical Depression 12-E, the HEC-HMS simulation results show that the maximum volume of flood water in the lagoon is $21.6 \times 10^{6} \mathrm{~m}^{3}$, as stated previously. Based on ground observations at the time of the event, we can fix the depth of the water in the lagoon during its deepest at $5.9 \mathrm{~m}$. This data point $\left(5.9 \mathrm{~m}, 21.6 \times 10^{6} \mathrm{~m}^{3}\right)$ is 
plotted as a green dot in Figure 12, showing that the HEC-HMS model matches up relatively well with the DEM-based results using ArcGIS.

In order to further validate the robustness of the parameters used in the HECHMS model, a sensitivity analysis was performed. Each of the 11 user-defined parameters discussed previously were recalculated at plus and minus one half standard deviation (that is, $+34.1 \%$ and $-34.1 \%$, respectively). To address individual parameter sensitivity and its influence on the model output, the One-at-a-Time (OAT) sensitivity analysis method was used. This is accomplished by changing one input variable while maintaining all others at their normal values, running a number of simulations (Hamby, 1995). Therefore, after calculating two new values for each variable, 22 new model iterations resulted, as shown in Figure 13. 


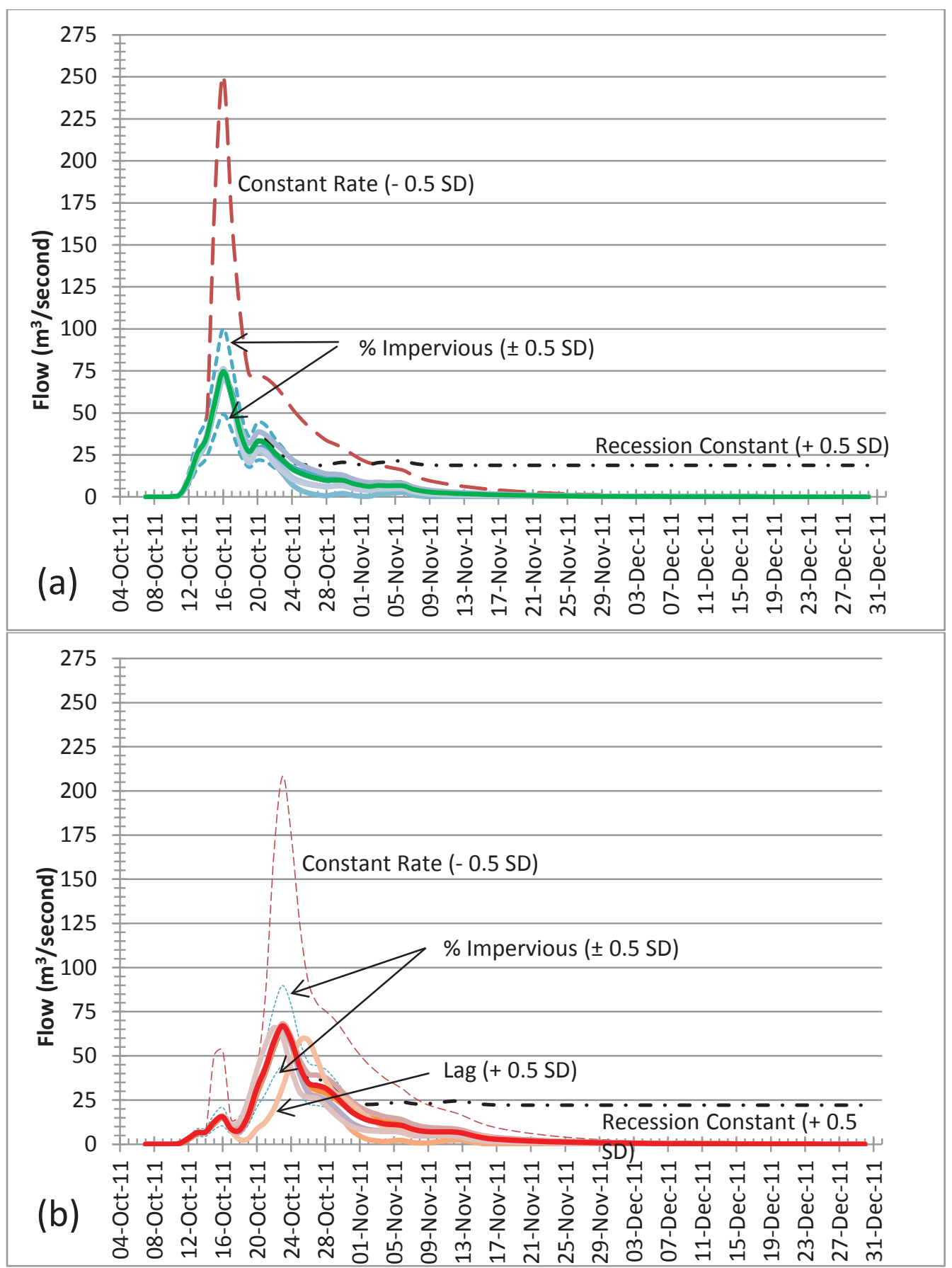

Figure 13. Results of change in modeled inflow (a) and outflow (b) found during a sensitivity analysis, which deviated $\pm 34.1 \%$ (one half standard deviation) from the values used in the model. The original Inflow (green) and Outflow (red) curves were overlain with the new Inflow and Outflow curves, with the largest deviations from the original curve labeled within the graph. 
From the sensitivity analysis results, we observe that most of the 22 simulations coincide relatively well with the values chosen for the model, suggesting leniency in the model parameters, when it comes to using poorly defined data. Most of the curves in Figure 13a follow the original green inflow curve, and most of the curves in Figure 13b follow the original red outflow curve (both seen in Figure 8). However, the sensitivity analysis identified certain parameters which had a more important relevance to the model results.

It was found that lowering the Constant Rate from the Loss Rate method parameters (which dictates the ability of soil to absorb rainfall), raising the Recession Constant from the Baseflow method parameters (which defines the rate of baseflow decay between storm events), and both higher and lower values of the percentage of impervious ground cover (typically cement covered urban areas that prohibit rainfall from entering the soil), are important factors that significantly affected the outcome of the simulation results. These key factors warrant better constraining, as even a small variation appears to have a significant impact on the final outcome of the model.

Another parameter worth investigating is the importance of rainfall distribution in the model. To this end, the total amount of rainfall during 12-E was evenly distributed over 27 days and the simulation was run again using this new rainfall data. The resulting highest net volume increase of water in the lagoon is about $9.0 \times 10^{6} \mathrm{~m}^{3}$. This is represented graphically in Figure 14. Since the depth of the lagoon during this theoretical flooding cannot be measured, a horizontal line showing approximate depths is used for the graphic representation. The simulation shows us that, with an even rainfall distribution, Tropical Depression 12-E would have only flooded 3 to 4 meters, rather than 4.9 meters. Hence, rainfall distribution is an important factor in the model, and has implications for hazard assessment and planning.

The model was also tested using rainfall data from Hurricanes Mitch (1998) and Stan (2005). Both these hurricanes caused large scale flooding in the region during their respective years. Their simulated highest net volume of water in the lagoon is plotted against a local farmer's recollection of flooding heights (taken from mud lines in his home and on his roof) in Figure 14. Hurricane Stan seems to match up relatively well, however Hurricane Mitch does not fit the volume versus lagoon depth line found using ArcGIS. This is likely due to the extent of the DEM map used in calculating this relationship line, as a balance had to be found in order to include as much of the lagoon's surrounding areas as possible, while still excluding the regional pools of flooding water that are unconnected to the lagoon. This seems to play a big role at higher volume/depth combinations.

Additionally, rainfall data from an unnamed rain storm in the area during September of 2012 was simulated. The author was present for this storm and witnessed flooding of about 1 meter, though no precise measurements were taken. This storm was modeled and yielded results of $4.2 \times 10^{6} \mathrm{~m}^{3}$ peak net volume and plotted as an additional data point on Figure 14 in order to further validate the preciseness of the simulation. The results from this September 2012 storm line up well with the relationship between volume and lagoon depth that was established, contrary to Hurricane Mitch. It appears that the model loses accuracy as the size of the storm, and therefore depth of flooding, increases. This is a drawback that should be 
addressed. It is believed that a higher resolution DEM (such as LiDAR) would eliminate much of the impreciseness seen here.

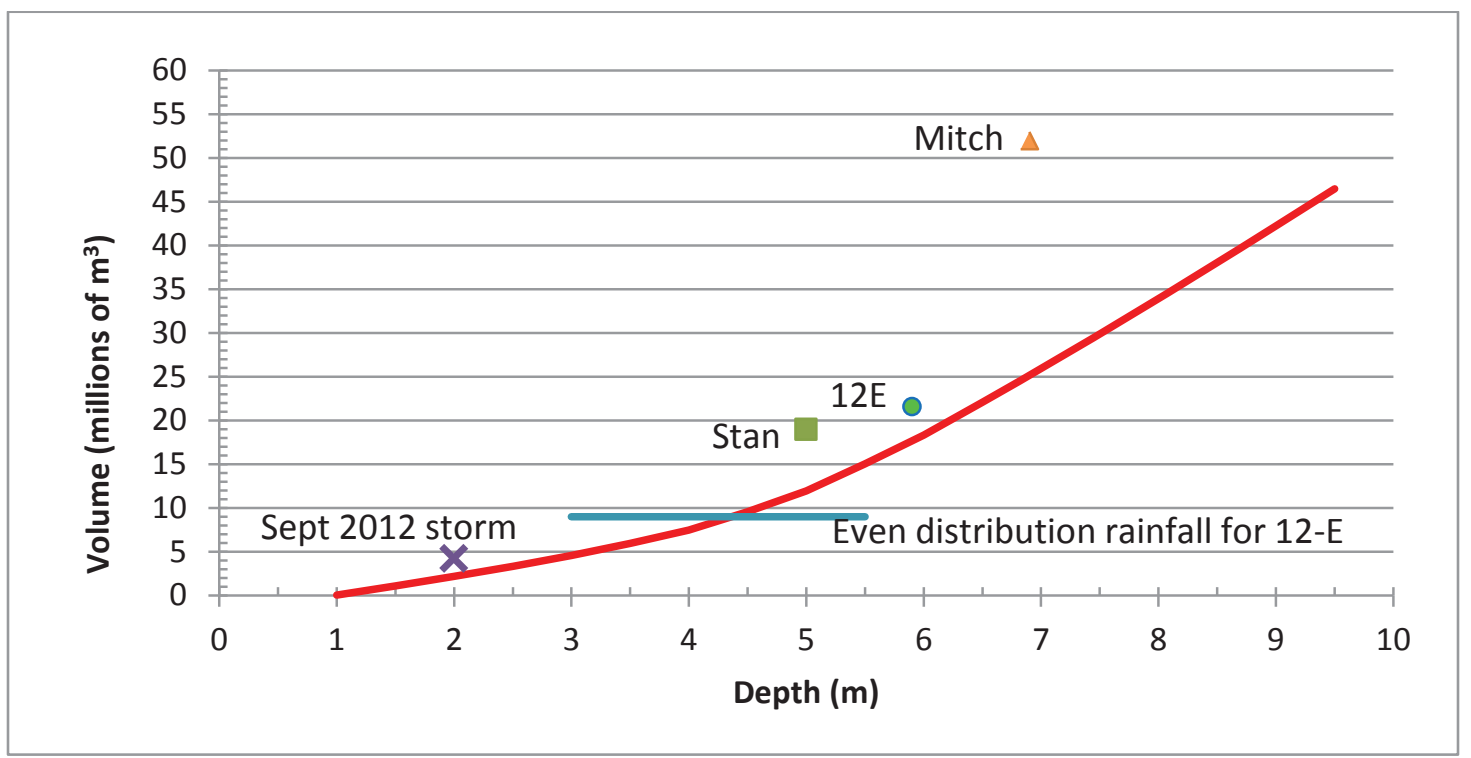

Figure 14. Additional simulation results using varied rainfall distribution patterns and other known flooding events. Peak net flow of additional water into the lagoon versus depth plotted, and compared against Tropical Depression 12-E.

\section{Remote sensing interpretation and validation}

The model produced consistent results from the hydrologic simulation and the mapping prediction of volume vs depth, because both are based on the same DEM. However, this is not the same as obtaining a true calibration. In order to accomplish this in the absence of quantitative ground-based data, remote sensing data was used. The HEC-HMS simulation and mapping prediction were compared with satellite image observations of the flooding from Tropical Depression 12-E. The surface area observed from the ASTER images can be compared to the surface area predicted by the simulation, if they are observed at the same time (with the same water depth).

The extent of the lagoon during the dry season in 2011 and flooding levels later in 2011 during Tropical Depression 12-E are shown in the ASTER satellite images of Figure 15a and Figure 15b. The delineated extents were transferred to ArcGIS, shown in Figure 15c and Figure 15d, and are presented against the simplified outline of the lagoon extent as seen in the original DEM (Figure 10). 


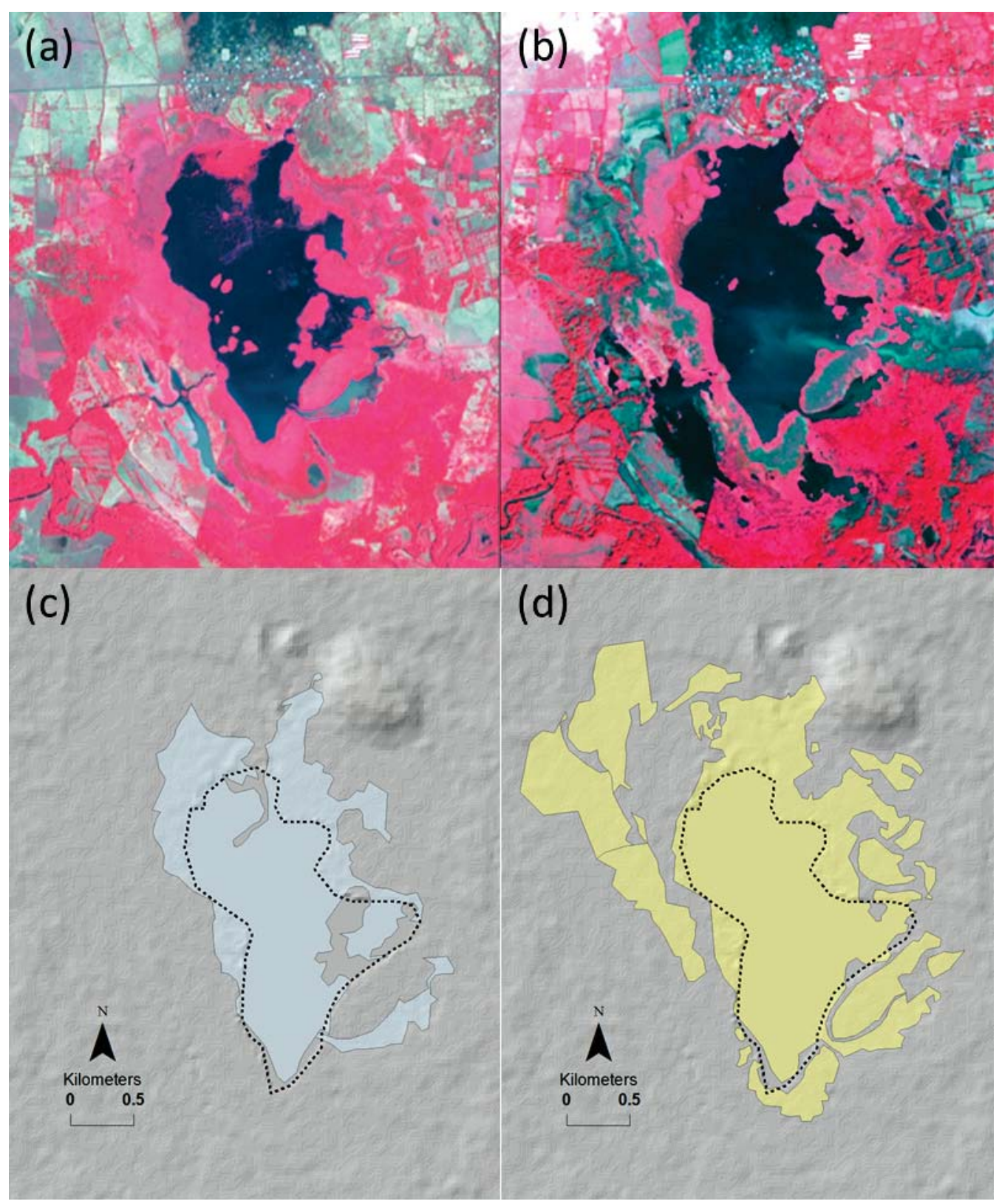

Figure 15. ASTER image and DEM visualization. (a) ASTER image from the dry season, March 3, 2011. (b) ASTER image of Tropical Depression 12-E flooding during the wet season, on November 7, 2011. Red is vegetation; darker colors are water. (c) Outline of dry season lagoon extent, taken from March 3 ASTER image, and projected onto the DEM. (d) Outline of flooded lagoon extent, taken from November 7 ASTER image and projected onto the DEM.

The surface area of the lagoon during the dry season, measured from the image in Figure $15 \mathrm{c}$, is $3.2 \times 10^{6} \mathrm{~m}^{2}$. The surface area of the flooded lagoon during Tropical Depression 12-E, from Figure $15 \mathrm{~d}$, is $5.3 \times 10^{6} \mathrm{~m}^{2}$. The depth of water in the lagoon during peak flooding of the event was observed to be $5.9 \mathrm{~m}$. This data point $(5.9 \mathrm{~m}$, 
$5.3 \times 10^{6} \mathrm{~m}^{2}$ ) was plotted as the blue dot on Figure 11. However, since the ASTER image was taken on November 7, 2011, this is a full 18 days after peak flooding occurred on October 20, 2011. The true depth of the lagoon on November 7, 2011, is unknown and likely less than that of peak flooding level. Therefore a line of potential depth values for the given area is represented by the horizontal blue line in the figure.

The ASTER image observes a smaller areal extent of lagoon flooding than the hydrologic modeling predicts. The discrepancy has multiple potential sources. This could be due to the effects of the lagoon delineation, done by the hydrologist. For example, the dark area to the south-west of Figure 15b was not included in the calculation of lagoon's extent in Figure 15d. Though this area appears to be flooded, there is no data on the depth (nor volume), and is not generally considered to be part of the lagoon. The same goes for the less clear scenarios in Figure 15b, as they are varying shades of gray. Whether these represent large shallow puddles or are, in fact, part of the lagoon is subject to user bias. The delineated extent in Figure 15d represents the extent to which the flooded lagoon limits were witnessed in person by the author. Another potential source for the lack of perfect agreement in the model and the ASTER-observed flood zones is that not $100 \%$ of the inflow/rain combo makes it into the lagoon. An unknown portion of this water volume is likely to be retained in shallow pools elsewhere in the sub-basin, or might have infiltrated into the soil, or could even have evapotranspired in the two and a half weeks since peak flooding.

It is therefore possible that the true values of surface area and volume are underrepresented in the curves from Figure 11 and Figure 12, respectively. This would potentially raise the level of these curves and change how well the HEC-HMS data point (green dot in Figure 12) and the ASTER derived data point (blue dot in Figure 11) fit the curve.

Solely comparing lagoon flooding to all the excess water in the Lower subbasin as predicted by the model does not completely reflect the complexity of the situation. Due to the lack of data constraints, it is very difficult to say whether the ASTER-observed flood zones agree in detail with the outcomes predicted by HECHMS and visualized in ArcGIS. While this study does not show a definite agreement between the ASTER and HEC-HMS derived end products, nor does it outright say it's impossible. With more data and better constraints, the prospect of an accurate match is very possible.

\section{Community perspective and interview findings}

It is one thing to be able to model or predict a flooding event that results from a large rainfall event. But the effect on people's lives and livelihoods is the truly important outcome. One goal of many hazard studies (such as the modeling performed in the previous sections) is to provide information that can be used to reduce risk to people and property, through an assessment of vulnerability and corrective actions to reduce vulnerability and risk. The undeniable truth is that people choose to live near the lagoon, despite regular flooding, for a wide variety of reasons. This section will explain in more detail the realities of what happens during an extreme flooding event (over 4 meters) in the community. 
Specifically, the case of Tropical Depression 12-E will be examined as an example of local residents' adaptation to these recurrent floods. Through the use of interviews, a survey, and participant observation, my social investigation has led to the conclusion that flooding has a significant role to play in the local economy, and so must be understood in that context. The adaptation to flooding as a routine has allowed development of community behaviors that must also be taken into account. The discussion on the inclusion of social data into the hydrologic modeling system raises the question on whether hydrological research alone may not be adequate enough for a holistic approach to flood characterization. These implications will be discussed more thoroughly later in the thesis.

Case study: Tropical Depression 12-E.

In October 2011 a deadly meteorological event known as Tropical Depression 12-E hit Central America and Mexico. In El Salvador, sustained rains dumped 1513 $\mathrm{mm}$ of rain - almost the equivalent to the country's yearly average - in just 10 days (UNCEPAL, 2012). Tropical Depression 12-E was not well predicted (Kimberlain, 2012), and ultimately resulted in $\$ 840$ million of recorded damages in E1 Salvador alone, drastically affecting $70 \%$ of the country, according to the United Nation's Comisión Económica para América Latina y el Caribe (Cepal.org, 2011).

I arrived in El Borbollón 4 months before Tropical Depression 12-E, and, as described above, acted as a participant observer before, during, and after this event. I saw how the community managed the flooding; how they dealt with, worked with, and incorporated it into their daily lives during the weeks of flooded waters within the community.

The 2011 rainy season in El Salvador seemed another typical time of year. As the end of the May to October wet season approached, almost all of the country's yearly average of $1513 \mathrm{~mm}$ of rain had already fallen (IFRC, 2013). The ground was saturated with what appeared to be the end of the regular yearly rains However, on October 6, 2011, the US's National Hurricane Center (NHC) spotted an area of "disturbed weather" a few hundred miles south of Mexico, over the Pacific Ocean (Beven, 2011). On October 11, 2011, heavy rains started falling over the country of El Salvador, and did not let up for the next 12 days (SNET, 2015). An area of low atmospheric pressure had built up to the point that on October 12, 2011, the NHC had designated it a tropical depression, as well as a warning that it might evolve into something even stronger (Brennan, 2011).

The soils, having already been exposed to all of the rains normally associated with the wet season, had long since reached maximum moisture capacity and could no longer absorb any of the rainfall. Nearly all of the regional precipitation therefore turned into surface flow, making its way into the Rio Grande de San Miguel. This river flows directly into the south-eastern portion of the Laguna El Jocotal, raising the waters steadily within the lagoon. A land owner on the edge of the lagoon reports that, for any given flood, "the lagoon fills slowly, (...) at roughly $5 \mathrm{~cm}$ per hour."

With sustained rains and more forecast to come, on October 14 the government of El Salvador declared a national State of Emergency due to the impact caused by Tropical Depression 12-E. At this point the community members in El Borbollón were 
paying very close attention to the rising water levels. Those living closest to the lagoon had already been affected and forced to leave their homes. Trucks and workers from the regional mayoral office had been put on standby, ready to assist with the evacuation. As a result of the slow rising waters, the evacuating families had time to pack up every single one of their belongings. Friends, neighbors, and local government workers cleared the house of all items: everything from bedroom furniture to kitchen appliances (Picture 1). The truck then brought the family to a household at a higher elevation within the community, well out of the range of the flooding. By the time the national government had declared a state of emergency, 77 households had already been evacuated, according to the official Park Rangers. Trucks, gasoline, and manpower from the mayor's office were used each time, at no charge to the family.

With the official government's acknowledgment of the rain and flooding disaster hitting the country, local schools were closed. Following protocol for large scale flooding events in El Borbollón, the school grounds were used to establish an emergency evacuation shelter for community members displaced by the flood waters. Volunteer workers, cots, blankets, water, and other emergency shelter items were brought to the school grounds from the neighboring cities of Usulután and San Miguel, each about $30 \mathrm{~km}$ away.

As the waters continued to rise during the following days, the edge of the water became a central place in community life. One community member later described to me in an interview the activities at the water's edge as "playing, laughing, even a form of entertainment!" With school not in session, the children had nothing to do but stand around and watch the water rise. The same went for the farmers who couldn't work the soggy fields, and the collectors of volcanic rocks as conditions were much too slippery to work safely. Only the fishermen continued to take their boats out into the lagoon to fish. The spot where the rising waters intersected the main road become the heart of the community. Fishermen anchored their boats as close to the new "shore" as possible (Picture 2). Local vendors even set up stands to sell their wares, such as the vendor selling a local food known as "pupusas" in Picture 3.

During the night, multiple community members would remain awake and observant of the water levels. Should the level rise too quickly, the official Early Warning System was deployed: five men in fluorescent orange vests would knock on the doors of the houses at imminent risk of flooding.

This process continued until the flood waters peaked at approximately 4.9 meters above dry season levels. This took about 10 days, peaking on October 20, 2011. At this point, roughly 1000 people had been evacuated from around 300 homes. Exact numbers do not exist since census data does not exist. The evacuees could not be counted by tallying people at the community's emergency evacuation shelter, either, because not a single person sought shelter there.

Through repeated exposure to floods, each family that evacuated their homes during Tropical Depression 12-E already had the experience of doing so. They had done it so often, in fact, that each already had a plan in place. Some families stayed with family in the higher parts of the community. Others stayed with friends or fellow church members. Many stayed in their secondary homes at higher elevation, which remain un-used during the majority of the year. The families had identified ways to 
react to flooding and had practiced their strategy in past flooding years. Whether they realized it or not, they had come up with an emergency evacuation plan. This is confirmed by the fact that the official emergency shelter set up in the local school remained unused for the duration of the flooding.

It was common knowledge within the community that the lagoon would flood during Tropical Depression 12-E. It was openly discussed, expected, and prepared for. A local Park Ranger, and lifelong resident within the flooding section of the community, says that floods are "relatively common (...). This always happens when it rains enough. It always leads to flooding." Up to 1 meter of flooding would be inconvenient for those who live at the edge of the lagoon, but ultimately irrelevant to the rest of the community. With sustained rains, severe flooding is expected to affect everyone in the community.

When the flood waters receded weeks to months later, the displaced families move all their belongings a second time - back into their original homes that are no longer full of water. As the houses in this flooding zone are typically built using cinderblock, the frame easily withstands the flood water's weathering effects. After a thorough scrubbing and occasionally a new layer of paint, the house returns to a very livable condition. In this way, families who live within the flood zone near the lagoon will often completely pack up and change households twice in any year that sees a large flooding event. This planned relocation was observed to be common throughout the evacuating families.

Ultimately, Tropical Depression 12-E displaced roughly one third of the households in El Borbollón (about 1000 people), but affected the livelihoods of all those living within the community, regardless of how far they lived from the lagoon. Across El Salvador, it affected over 1.4 million people. Just under 60,000 people were forced to evacuate their homes, with at least 35 confirmed deaths and dozens of injured (IFRC, 2013).

Based on my field notes, a survey, multiple interviews, and personal observations, there are four recurring themes that stand out. In the following sections, I examine my findings within the community regarding (1) household strategies to manage risks brought on by flooding, (2) the economic ramifications of flooding, (3) reliance on the floods, and (4) the idea that floods have become habitual. 


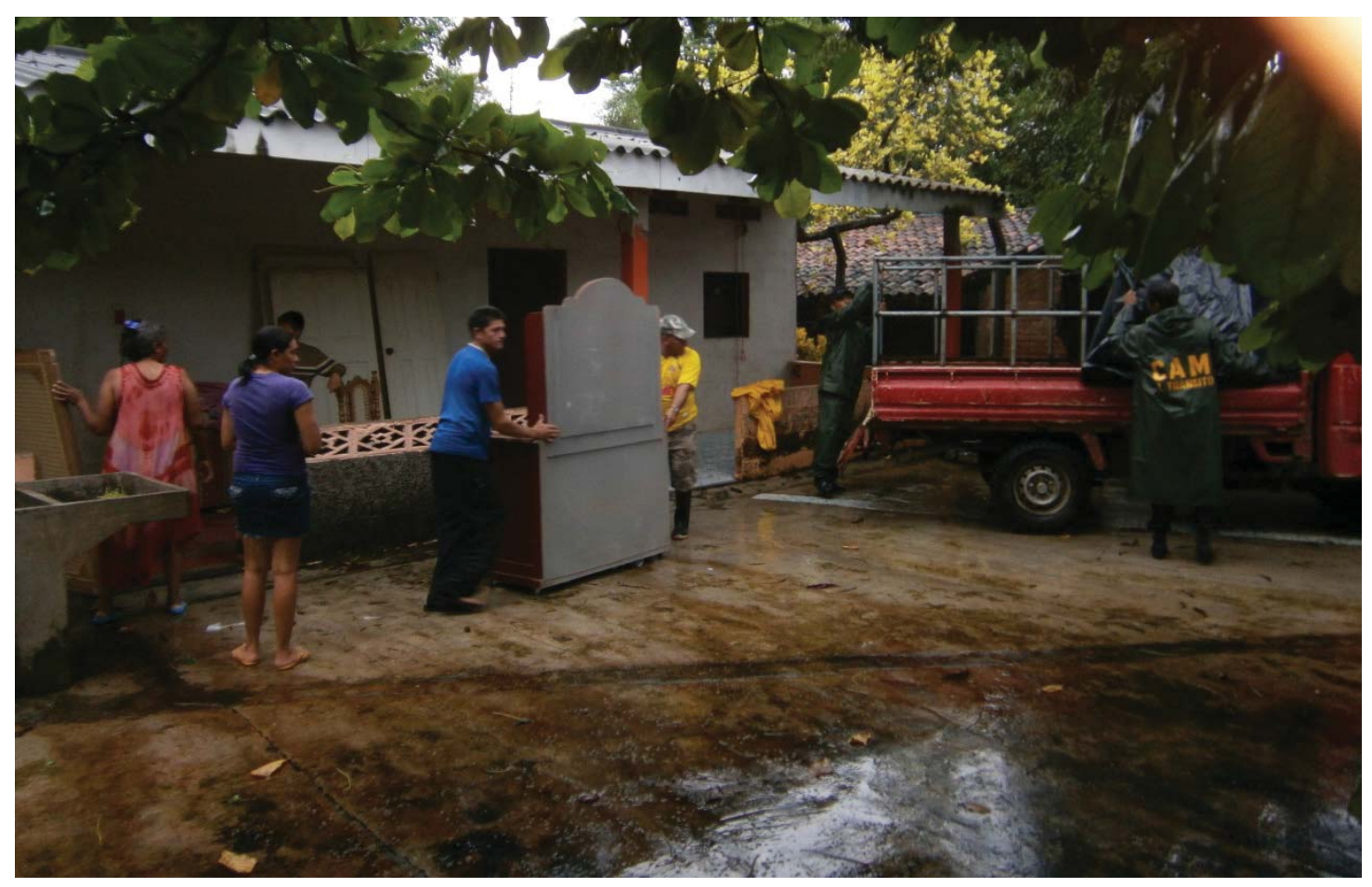

Picture 1: Family moving out of home as flood waters slowly rise and reach base of house. Official truck and personnel help move furniture

Household strategies to manage risks brought on by floods

Households within the community have found different strategies to manage the risks brought on by flooding, which they employ year after year. Community members fundamentally alter their day to day lives to coincide with the varying water levels. For example, families who own boats will simply follow the rising waters and moor their boats at the water's edge, regardless of whether this happens to be at the usual dry season dock or whether it reaches higher topography as far as a kilometer inland due to flooded waters (Picture 2 and Picture 3).

These same families with boats, most of whom are fishermen, will continue to fish despite the flood conditions in the lagoon. According to one interviewee, most fishermen within the community will alter their usual fishing routes and in favor of different areas that prove more fruitful with the changed water depths. In personal discussions with members of the fishing co-op, it seems that most participants even lay claim to specific fishing areas that only appear with high water levels, such as in the street or yard in front of their own flooded households.

Most community members who live near the lagoon find it practical to maintain their primary household within the flood hazard zone. There are many advantages to them for doing this. First of all, families typically live near each other, as it is customary for offspring to build homes adjacent to their parents on family owned plots of land. Moving to a new area would break generations of bonds established between families, friends, and neighbors. A sense of community and sense 
of place is a well-documented characteristic that ultimately encourages and increases adaptive capacity (Paton, 2006a; Cutter et al., 2008).

Additionally, moving out of the area well ahead of the rising flood water offers very few real advantages. If a family chooses to relocate well in advance of the incoming flood waters, they will do so on their own. However, a local community member and former Park Ranger explained that families will often wait until the water levels are very close, knowing they receive the help from local government and aid organizations to move their belongings out of their house for them, free of charge. He explains that "there are people who take advantage of the trucks and manual labor provided by the mayor or army to transport their belongings from their first house to their second house." In this way, there is a strong incentive for families to wait until the last possible minute before leaving their homes. A Park Ranger explains that "people get mad. We tell them the lagoon waters are rising and that they need to leave, but they just get mad at us" since, by leaving their homes early, they will not receive the government truck assistance which is tasked only with helping those in imminent risk. This idea of planned relocation extends past household strategies to deal with floods, and into the following sections on the local economy and reliance on the lagoon, which will be discussed later.

Repetitive exposure to the same hazardous event increases the ability of the community members to build an adaptive capacity (Paton, 2006a). Large scale flooding has become such a recurrent event in El Borbollón, it can be said that they have adapted to the style and pace of the flooding in their area, effectively managing the risks brought upon them due to flooding. 


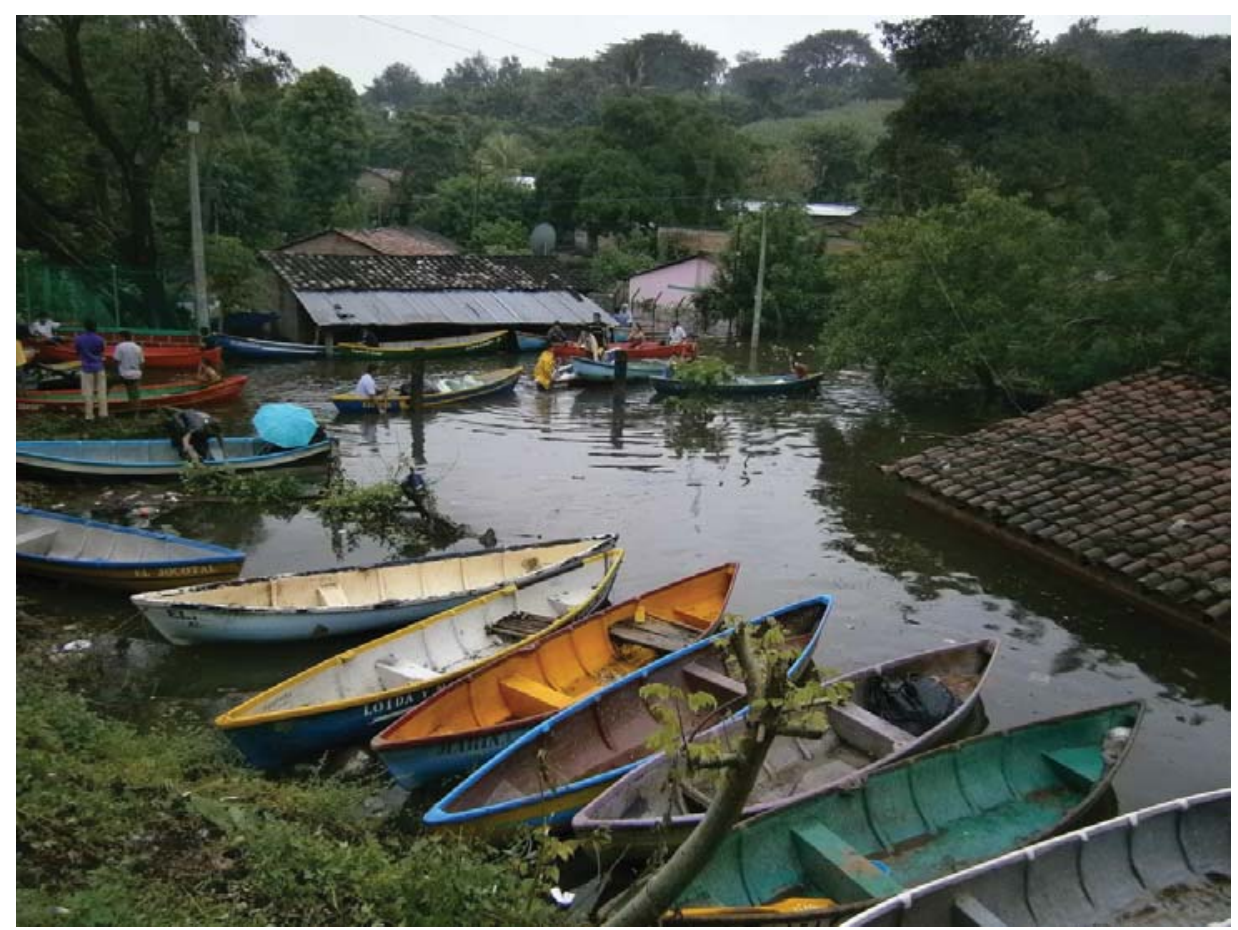

Picture 2: As the flood waters slowly rise, the makeshift dock at the water's edge rises with it.

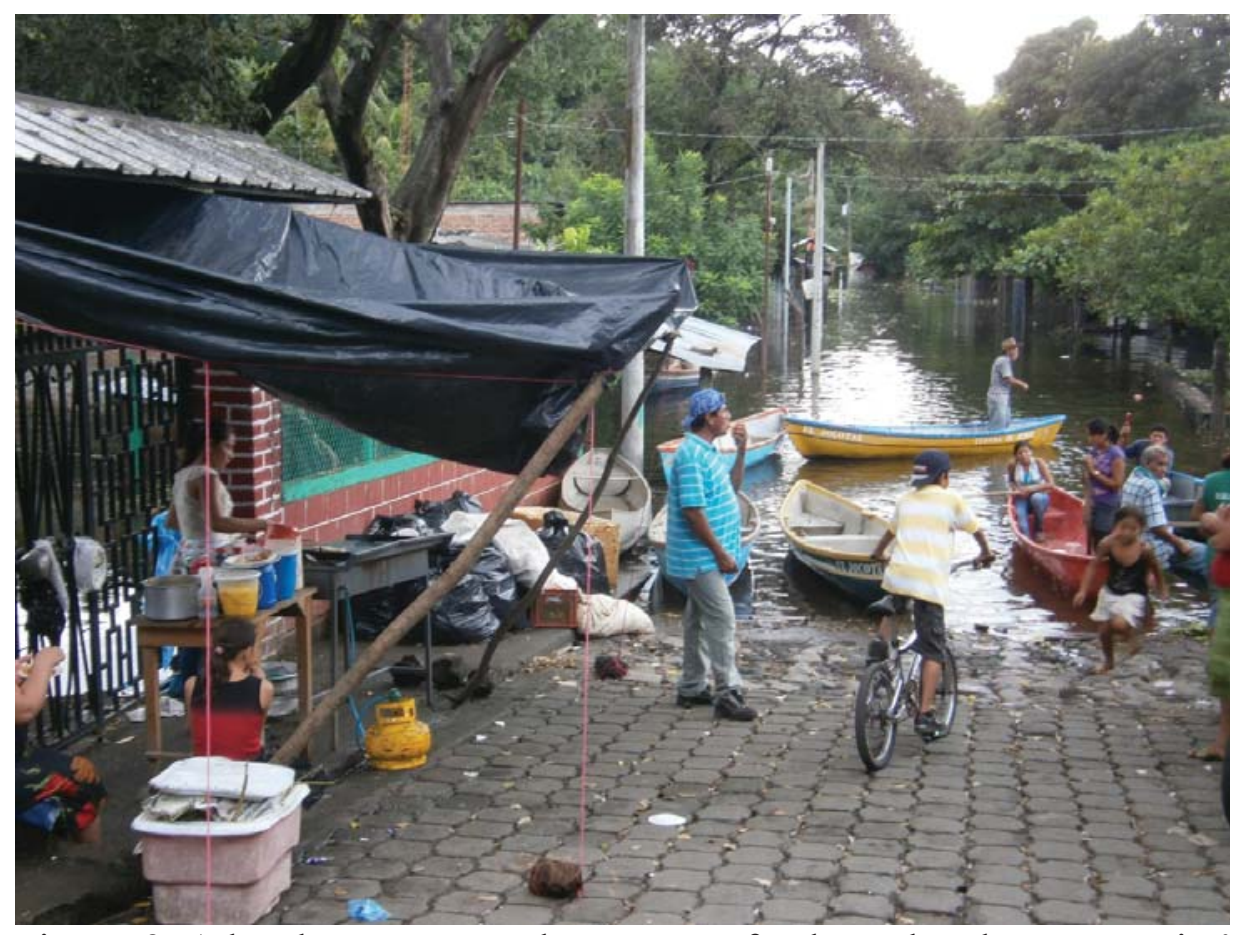

Picture 3: A local entrepreneur has set up a food stand at the community's temporary dock, along the road. 
Economic ramifications of floods

There is no doubt that the community of El Borbollón has built an economic life around the water. The lagoon provides fish, irrigation for crops, and drinking water for livestock. However, some have realized that large flooding events can also be turned into profits.

Disaster relief aid has become an economic driver for the community. According to multiple sources interviewed, flooding ultimately brings "clothing, food, building materials, and money" into the local economy. This relief aid system not only stimulates local commerce, but provides a covert source of income for families. By adjusting their daily lives in order to benefit from all the opportunities provided to them by outside aid sources, many capitalize on the relief aid system as a form of income that they can count on.

One reason so much aid arrives in the community is that the images of the flooding tend to be quite sensational. Photos and videos of water levels reaching house roofs (Picture 2 and Picture 4) make their way to national and international press organizations, and are widely distributed. Not fully aware of the slow process in which the waters have risen before the photo was taken, an abundance of food and clothing pours into the community from charity groups, churches, regional government, and national and international NGOs. Outsiders to the community think it is a crisis, when in reality the community works almost perfectly in sync with the flood waters.

Fortunately for the community, Tropical Depression 12-E occurred a few weeks before a local election, prompting additional largesse. One of the political parties loaded up a truck and handed out 15-pound bags of dried food in an effort to earn votes. The opposing party did the same thing about an hour later. I watched as community members received aid from one of the trucks, and then immediately got in line to obtain a second bag of food from the second truck.

Some organizations, lacking sufficient manpower, leave entire shipments of aid (sometimes up to hundreds of pounds of supplies) directly with people they have identified as community leaders, expecting it to be distributed accordingly. One interviewee describes how this system is regularly utilized, as some people will pretend to have an official role (even dressing up to appear more realistically like an authority figure), just to have massive amounts of aid dropped directly at their house. This aid is then re-sold (often in the nearby bigger towns) and turned into cash. "They sell it," tells one of the locals interviewed, "they receive a mountain of aid and they resell it. They resell all of it." Local residents from unaffected neighboring towns will often come to El Borbollón (by bus if need be), in order to receive a share of the handouts.

A community leader describes to me the anecdote of a Spanish NGO that visited the community in the early 1990s. The NGO, whose name neither he nor anyone else in the community could remember, offered to relocate every family living within the flood hazard zone. They offered to buy their flood-prone land from them, to purchase new land for them at higher elevations, and even to build new homes on their new land. All this free of charge to the community members. A vote ensued, and the proposal was rejected by community consensus. This shows exactly how much the majority of the community appreciates and depends on the lagoon flooding. They 
calculated, perhaps accurately, that the continuing source of income generated by the flooding of their low-lying homes would be more valuable than a one-time land swap.

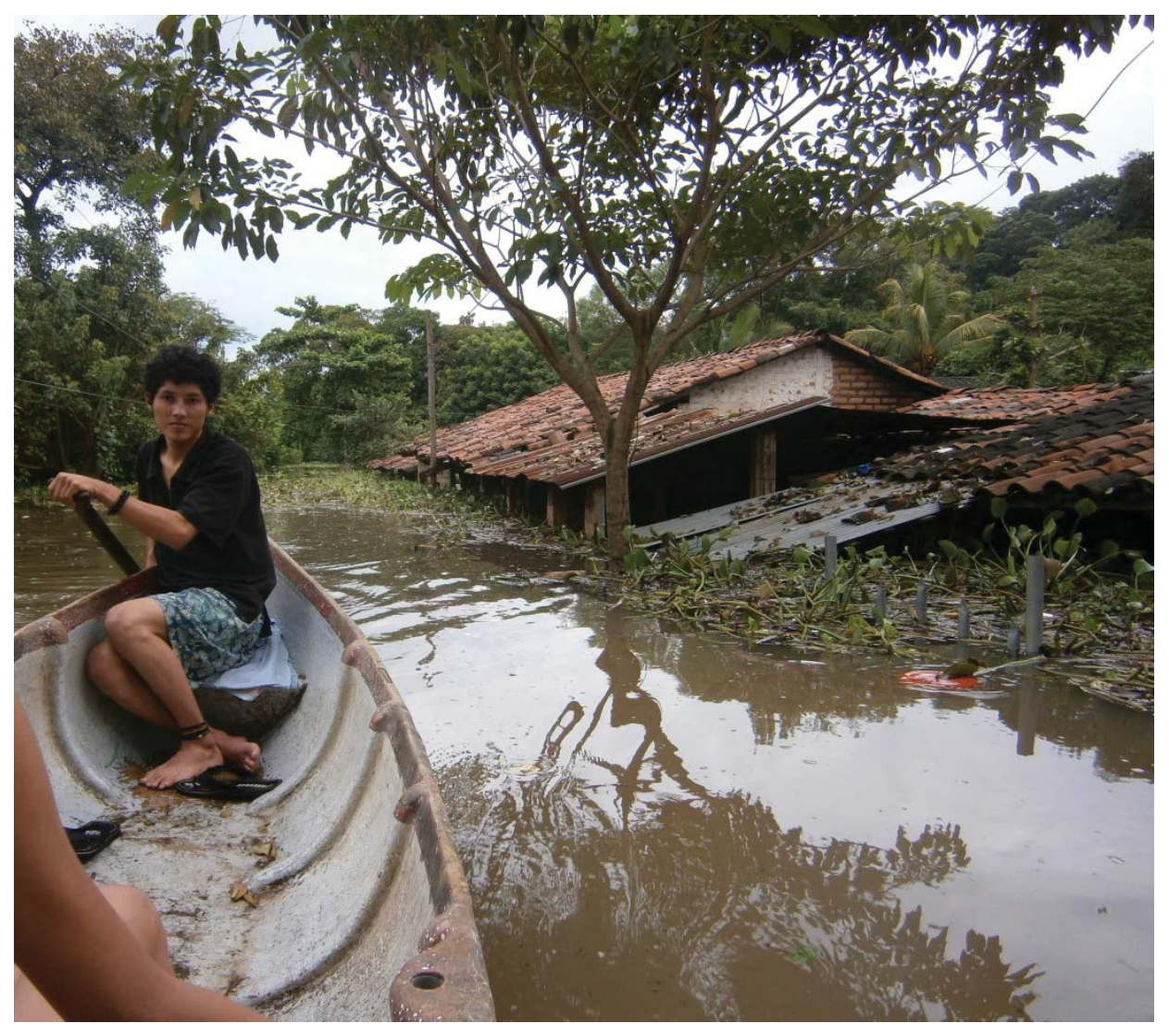

Picture 4: Floating down the main street during 12-E flooding.

To illustrate El Borbollón's relief-based economy, the following scenario provides an example. I will draw on multiple sources and from a collection of stories and anecdotes, all of which were described to me as being true. Consider a new family unit that wants to start their own house. Despite being fully aware of the recurrent flooding, they build a house at the edge of the lagoon. For the majority of the year, it is closer to their daily activities and therefore more practical for the family; they have a shorter distance to walk to the water in order to wash dishes, wash clothing, and get to their fishing boat, than they would if they built on higher ground. The potential rainy season flooding poses no life-endangering threats, and, while it can be an inconvenience, ultimately offers more benefits than drawbacks.

The family purposely builds their new house well within the hazard zone knowing that it will flood. This way, they will be entitled to a large portion of supplies as aid, which will be resold almost in its entirety. Right before the rains arrive, they will be sure to casually plant a small field of corn next to their house, hoping for a flood. If they are "lucky" and the waters rise, their crop will be destroyed and they will 
be entitled to compensation. With the extent of the original crop unverifiable, they will routinely claim up to five times what the crops were actually worth.

Our example family will make their living in this way, by using the opportunities available to them. Relief organizations come and offer handouts, and not many residents will turn down free food. Is this taking advantage of the system or just accepting it and working within it? This is typically human; in an economy that is limited in resources (as is the case with the reliance on natural resources such as the Laguna El Jocotal), families adapt by utilizing every available resource and strategy to make ends meet. This is not a case of graft in which families enrich themselves beyond their needs. Interestingly, it seems that in El Borbollón's underdeveloped economy, some families are able to cobble together remittances, fishing/agriculture, and utilization of emergency aid to make a living. There is no doubt the system is not ideal, since it does not always get aid to the people who may indeed need it, or delivers supplies to people who horde and re-sell it. The family receives large amounts of dried food, clothing, and ultimately money from the aid, on top of a monthly money transfer from a relative working in the United States. This provides enough income for the family to survive until the next rainy season, as family survival depends upon making use of all forms of possible income. It is not about becoming wealthy, just survival.

In fact, negative economic consequences do not appear in the community of El Borbollón during flooding, rather the opposite is the case. The true "disaster" occurs in a year when there is NO flooding. The local economy does not receive the stimulation of the influx of aid materials, and the following year will be much more economically difficult for the family, as they will not have the financial boost provided them during flooding events.

Including economics into flood-risk models is a good addition, which arguably makes the model more complete. This is done to a certain extent (Jonkman et al., 2008), but not usually in areas with so little infrastructure, and where the small-scale economy includes regular bartering and favors for friends.

\section{Community reliance on floods}

The strong links between the local economy and relief aid have created a marked dependency on the lagoon. Although it may not have started this way, families have learned to accept, use, and depend on the aid handouts for much more than just temporary relief. According to multiple interview sources, some people can routinely live up to a year off of aid relief. An interviewee who lives within the flood zone explains that during days of extreme flooding " 4 trucks come (to the community), for example. In the morning a truck comes at $9 \mathrm{AM}$, and each affected family gets a ration. That truck leaves. Later, at like 2 PM, another (truck arrives). They give their rations to the exact same families. This means that virtually every head of affected household receives, on a given day, 4 packages (containing dried food goods and clothes). (...) If we experience 10 or 15 days of flooding, he has received almost enough food (and clothes which can be resold and turned into money) for a year."

Additionally, an interviewed community member quotes an unknown study stating that $80 \%$ of families in the community receive remittances. That is, $80 \%$ of 
people already receive a certain amount of money from their relatives working abroad. Sixteen years ago, a study found this number to be closer to $33 \%$ of the families within the community (Benitez et al., 1999). Accounting for updated emigration numbers, and assuming the true number of families receiving remittances is somewhere in between $33 \%$ and $80 \%$, once we add this to the benefits from relief aid into the average family's yearly earning, it is easy to understand that families could live for a year off of this combination of assistance. In this context, it is easy to understand why people are "eager" for a flood to occur, according to another interview. This "disaster" is hoped for by much of the community, not feared the way most people view extreme natural phenomena.

Reliance on aid isn't viewed as a bad thing in the community. Rather, it is seen by some as the smart thing to do. With free food being handed out, families of limited means will eagerly accept the offer, regardless of how much they have been affected by the disaster. The community uses the resources offered to them, and this is seen as logical.

\section{Effects of habitual flooding}

During Tropical Depression 12-E, the regional government canceled classes at the local school, using the classrooms as an emergency shelter for all those who were displaced by the rising waters. Volunteers were brought in from cities over an hour away, in order to prepare for and accommodate the hundreds of refugees that government officials expected. At the height of the flooding, a minister from the capital even came to visit the shelter, assuming it would be full of refugees. The minister and her entourage were surprised to find out that, of the $1000+$ community members who were forced to leave their homes, not a single one was using the government-funded shelter. Apart from the usual issues such as comfort, privacy, and safety that sometimes plague temporary emergency relief shelters, it was empty in this case is simply because no one needed it.

Independently from the removed officials who decided to initiate the emergency action plan and set up the shelter, everyone in the community had already created their own action plan for the occurrence of flooding. Having experienced the phenomenon first-hand so many times, they already had their own managing strategies in place.

In fact, moving out when the lagoon waters rise drastically comes has become a community event. It is sometimes even considered fun, as described previously by an interviewee. The children are out of school and the parents cannot work during the heavy rains. People gather at the edge of the water and spend their days with their friends watching the water rise. The pop-up business in Picture 3 shows how the community revolves around the makeshift dock that varies with flood water height. This technical adaptation strongly supports the routine nature of social adaptation.

Further indication that community members have become desensitized and accustomed to flooding can be seen by their unfazed attitude towards these events. One local Park Ranger and lifelong resident of the flooding section of the community says that floods are "relatively common" and "the people do not fear them. They are not scared because this always happens." An obvious lack of fear plays a big role in 
how the community members perceive floods (Slovic et al., 2004). A community leader explains that "outsiders believe that the people here are afraid (of the lagoon). But the people here, they are accustomed to it. They are not scared. Children, from the age of 6 years old already know how to swim. There is no danger that they drown." Unlike most Salvadorans, everyone is this community is taught to swim at a young age. Because the flood waters rise relatively slowly, there have been no deaths in the community associated to the flooding. Another local resident interviewed told me that the local residents "don't suffer, and there is no danger."

The residents of El Borbollón are used to floods. They have become desensitized because the local conditions rarely lead to life threatening situations. Floods are so often seen and discussed that there is no longer any associated stigma. In unofficial discussions with classes in the local middle school, I learned that the vast majority of the students believe that living with regular flooding events is normal, that relocating during most wet seasons is ordinary, and that nearly all of them expect future floods.

\section{Discussion}

The hydrologic and social research performed in this study examines two sides of the same coin. Each describes the effects of flooding on the community of El Borbollón in its own way, heedless of the other. We have created a hydrological model of the area for the case study, and we have examined community attitudes towards the flooding. Next we will discuss the pros and cons of each method before delving into a dialogue of whether or not they work in a positive partnership.

The results of the hydrological analysis tell us that the HEC-HMS modeling and the mapping produce results that, at first, seem reasonable. However, the remote sensing validation of the hydrological analysis was only marginally successful, suggesting that errors in the input data for the model are too large for rigorous study in this case. The sensitivity analysis also tells us that the model is less effective for larger scale rainfall events. One possible source of error could be the DEM resolution of 30 $\mathrm{m} \times 30 \mathrm{~m}$; this may not be sufficiently precise for the model to produce adequate results. Another reason for the discrepancy could be due to the date of the ASTER satellite image. In Figure 9 we found that peak flooding occurred on October 20, 2011, while the earliest suitable ASTER image available and used to delineate the flood was taken on November 7, 2011. It is possible this had a noteworthy impact on the delineation results.

Another potential issue with the HEC-HMS model simulation is that it was not complex enough for this type of situation. Due to a lack of data, as is common in many places worldwide, the wildly varying elevation, climate, land use, and soils types were assumed to be uniform in nature. Daily precipitation values collected in the central sub-basin (location of rain gauge can be seen in Figure 7) did not take into account the more substantial rains probable in the mountain range of the upper sub-basin.

An important element not factored into the simulation is likely to be evapotranspiration, given the tropical location of the study zone. The simplest approach to determining evapotranspiration is the Thornthwaite-Mather model which relies directly on precipitation, temperature, root zone depth of vegetation, and soil 
field capacity (Alley, 1984). However, due to the hugely varying elevations, soil types, and flora within the basin, any attempt to estimate evapotranspiration would produce an impractical range of values. During the wet season, and at tropical latitudes, Schellekens et al. (2000) suggest an average evapotranspiration rate on the order of a few millimeters per day. Given the relatively short duration of Tropical Depression $12-\mathrm{E}$, the effects of this were assumed to not be essential to the model.

The remote sensing observation and computer simulation do not agree perfectly, but we note that there is a lot of potential error involved in both methods. The errors that we cite in the preceding paragraphs all tend to predict that the ASTER image under-estimates the flood area (because it was obtained late in the event), and the modeling may over-estimate the flood area (by ignoring loss by evapotranspiration, and accumulation of water within the Lower sub-basin but outside the lagoon). The results as provided agree, however, to within a factor of two.

The ASTER images prove especially advantageous as they can be retrieved and analyzed remotely. Very little field work is necessary using this analysis method, as networks of fluviometers and pluviometers aren't required. Therefore, the relatively low cost and high reproducibility of ASTER satellite images is convenient in an area that has little data and many disasters. One could organize a workflow for future projects that iterate through reasonable (unmeasured) input values until a good fit with ASTER images is obtained. This was beyond the scope of the present study, although the sensitivity analysis begins to attempt this.

The sensitivity analysis showed the necessary circumstances where the results of the simulation would be different. These key factors need to be better constrained, as their impact on the model is significant. The model seems to lose precision as larger storms with greater flooding is modeled. The effectiveness of this model therefore lessons correspondingly with the increasing magnitude of the storm modeled.

Running the simulation using rainfall data from other, known, rainfall events proves that changes in the rainfall distribution pattern are important. The model shows that, if Tropical Depression 12-E's rain had been more evenly distributed over the course of its life, the severity of resulting floods would have been much less pronounced. This has value for emergency planners, meteorologists, and flood modelers.

Over all, using two different approaches to flood modeling has proven useful. Had we only used simulation and mapping, for example, we would have accepted the results without continuing to question the outcome of the simulation, unaware of the shortfalls that become apparent in comparison with remote sensing observations, and through the sensitivity analysis. Ultimately, with greater data inputs, this form of modeling could be very useful in the conventional delineation of flood zones and assessment of related hazards in the community of El Borbollón. Unfortunately, social research tells us that a precisely defined flood hazard boundary map would be largely ignored by the community, regardless of its accuracy or precision.

Even though the model lacks precision due to uncertainty in the poor quality of the input data, it is still very relevant to the other actors involved in the relief and prevention efforts. My evaluation may not be useful to the community of El Borbollón in the short term, since they have found the means to adapt to flooding. However, it 
still provides value to others involved in the relief and prevention efforts. Even though a traditional flood delineation map not be useful to the community members, the regional modeling may be important to future hydrologists who wish to refine and enhance the model. Government scientists can use this data as a way to look at the potential scale of flooding, where information of the magnitude of an event may provide more important insight than the details of flood demarcations. The most sensitive factors in the modeling, found during the sensitivity analysis, would benefit from additional studies (and funds) to better constrain the limits of the simulation. Aid NGOs could focus their efforts on programs that address actual community needs, rather than unnecessary maps.

Along with the modeling and simulation data, the social data also has relevance for a wide variety of audiences. The traditional definition of risk is the probability of negative consequences (Knight, 1921; Oliver-Smith, 1999). Based on the social science research of El Borbollón's response to flooding, the community seems to have fewer negative consequences to flooding than assumed by the state. Because of this, the state seems to perceive it as a risk with negative consequences, which in turn fuels the relief aid from the government and others. Clearly this is part of a larger picture, as so many (fully aware) people choose to live within the flood zone. It appears that the outsider perspective on the community's vulnerability is artificially high, furthering our point that the routine flooding in El Borbollón does not fit the traditional definition of a natural disaster.

Conclusions from the social research find that, after viewing the ways in which households manage risks brought on by floods, the community has adapted to deal with recurrent floods through various cultural and economic strategies. At the community level, adaptation means being able to preserve the existing way of life in the face of anticipated flooding events, which El Borbollón accomplishes.

Furthermore, in small communities populations are forced to live, work, and grow side by side, often creating generations of bonds between families. Several studies (Paton, 2006b; Pearce, 2003; Mendis et al., 2003) have shown that a high level of community interaction, participation in group or club activities, and/or social action groups is a good forecaster of that community's ability to adapt to hazards. Adaptive capacity is increased even if such activities are unrelated to disaster response preparation, as the community will already be accustomed to jointly working through problems and overcoming local issues. This readiness and experience will translate over to real time disaster response and resiliency (Paton, 2006a). Therefore, adaptive capacity is already higher than average in small, close knit communities such as El Borbollón.

We can also conclude that the economy of El Borbollón is intimately linked to relief aid. Based on the eagerness of many community members for large scale flooding and the fact that aid is the primary source of income for some families, it appears that a lack of flooding (and flood response) would be more disastrous to the community than any level of flood waters. Unfortunately, there exists discrepancy in the vectors of aid distribution. Some families are able to take advantage and receive more aid than others. This creates friction between those who live in the flood zone and are entitled to aid versus those who live higher up, outside of the flood's reach. Those who leave the hazard zone of their own accord are not rewarded in any way, 
and in fact suffer by no longer receiving a portion of the aid. There is incentive to stay within the flood hazard zone and perpetuate the system currently in place. This understandably creates a division within the community. Despite this rift, most community members gladly welcome the influx of aid into the zone.

This adaptation to flooding events and weaving of relief aid into the local economy has created a situation in which the community would be hard-pressed to survive without regular flooding events. A widely accepted philosophy of reliance and dependency on outside aid has been created and strengthened through decades of flooding events and response aid. According to elders within the community, the first large flooding occurred with Hurricane Fifi in 1973, and has revolutionized the economic drivers within the community.

There is a demonstrated lack of fear vis-à-vis flooding in the community. The appearances of technical adaptations (such as the makeshift dock and mobile food stands synced with the shifting water levels) also suggest a complacent regularity of the flooding. All these reasons, plus the community's congregation on the edge of the water as the de facto town center proves that this situation in El Borbollón is, in fact, a routine.

Based on these conclusions drawn from the social research, natural disaster relief must include the perspective of those affected. To model the hydrologic behavior of the lagoon during a flood and not the community's behavior is to portray an incomplete representation of the situation. This is especially true in naturalresource based communities (Flint \& Luloff, 2005). In El Borbollón's case, this means a better understanding of local motivations and reasoning. This tactic by the local residents to rely on the lagoon as both a source of food and source of relief-based income is all the more surprising as locals believe the lagoon has a limited life. The Park Rangers, who arguably have the best local knowledge of the lagoon, fully believe that it will dry up within 30 years, much as the nearby Laguna de San Juan. While the Park Rangers may not fully grasp the far reaching implications of global climate change, they are acutely aware of changes in the hydrologic cycle that affects the lagoon. They may not understand why, but they see the empirical evidence of it. Laguna San Juan once contained a sustainable amount of fish, according to locals, but is now a wet field of tall grass.

Social data has the potential to significantly enhance the usefulness of the hydrologic model in multiple ways. As stated before, including social research findings into the early guiding principles of hydrologic modeling leads to a much more effective and valuable tool for flood hazard assessment. In the case of El Borbollón, for example, results of an ethnographic study preceding the hydrologic flooding would show that a traditional approach such as mapping the extent of flood hazard zones of the community would be completely ignored by residents. Local knowledge and past experience has already created an engrained notion of flood risk (or lack thereof). The true risk associated with floods, known by all the community members, comes from water borne and mosquito transmitted illnesses. The lagoon waters rise and mix with sources of contamination such as trash, latrines, fertilized fields, and untreated sewage water from the nearby upstream city of San Miguel. This directly affects the food chain of the lagoon's fish, which is the main source of food for local residents. Many 
livestock died during hurricane Mitch, for example, as they drank the contaminated water (just as the community members do) and ate the contaminated grass that was exposed once the water levels receded. The increase surface area of the lagoon waters creates ideal conditions for mosquito proliferation, directly increasing the number of cases of dengue fever and malaria seen in the community. As one interviewee stated, "there is no risk of drowning. The true risk comes from illnesses, (such as) fungi on the feet or respiratory problems."

Additionally, social research would permit local and regional government planners to avoid creating costly and time consuming elaborate schemes for relocation. This is ideally done by enhancing existing capacities (Anderson \& Woodrow, 1998). As known by local residents, emergency evacuation shelters go unused and simply represent poorly appropriated funds.

Perhaps most importantly, this social data will help find answers on how to change perceptions and behaviors to avoid the annual catastrophes and adjust the economic drivers to create more sustainable and logical benefits for the community, as well as help change erroneous attitudes of some government officials.

Using a case study approach raises questions as to how representative this specific situation is in a larger capacity. Stepping back and considering the community, flood event, and hydrological arrangement presented here, we see that similar situations present themselves around the world. As discussed previously, adaptive capacity is cultivated and improved with repeated exposure to similar hazards. Considering the planet's continuing overpopulation combined with the influence of climate change, it is reasonable to say that lessons learned in the case of El Borbollón could be exported and used in similar cases around the world.

At its core, social research examines cultural aspects of the community. These cultural factors aren't necessarily something aid or government agencies should aim to change through risk mitigation planning process, but they have to be taken into account when appraising risk and creating risk reduction and disaster recovery plans. One important consideration in this case study is that the underlying priorities of those affected by natural disasters may be based on a completely different reasoning and different point of view than that of aid agencies and outside disaster aid workers. For example, after a disaster occurs, money and investment comes to the community often in the form of training workshops. The training sessions tell the community how to prepare for and live with floods - a situation they are already very familiar with. They learn little from these workshops that outside NGOs assume they need. And ultimately the community members do not have anything to show for this money that was earmarked to help the area.

\section{Future work}

There is much potential for future work in the area. The results of this study were obtained using very small data inputs (a DEM and a single daily rain gauge). With more data, it should be possible to provide a simple, graphical way for flood prediction based on real time regional rainfall amounts. This would be possible with precipitation data from other flooding events of known depth. Each separate event would generate a single data point: cumulative precipitation over time and flood depth. 
With a large enough data set, it would be possible to constrain the basin's hydrologic response and ascertain its sensitivity to total precipitation and to time. With oftrecurring floods, El Borbollón is the ideal site to collect these date points, leading to a better understanding of regional hydrology. Additionally, a Monte Carlo simulation could prove useful in pinpointing the key flood producing variables and dependencies between them, to derive flood frequency curves.

There are many variables within the HEC-HMS program, and many unknowns in the study area. Through tweaking different variables, it is very likely that there are multiple input models that would produce the same results (matching the apparent flood area). Therefore, we have less confidence in the hydrological modeling results, due to the non-uniqueness of the situation. Because of this, the model is not as useful as it could be for planning in future flood events. The predictions are useful for community response, but more data is needed to better constrain the hydrological processes at play. Specifically, additional precipitation data during other flooding events would be useful in creating a flood probability graph that could be given directly to the community. Each of the key contributing factors found during the sensitivity analysis should also be better constrained, and warrant additional research to ensure their accuracy.

Of course, there is much work that can be done at the community level. Sustained education programs and public outreach efforts are vital to allowing cultural beliefs to evolve naturally and in tune with the local surroundings. Identifying more worthwhile aid delivery vectors is key, as is understanding the local influences at play when obtaining disaster aid relief.

This research suggests that flooding disasters are routine and that families have adapted well to this almost yearly event. However, the situation has become increasingly complex since disaster aid is now an important part of the local economy. This aid is what allows local households to survive. Changes in current levels and methods of disaster relief will have consequences that must be addressed. This reliance on disaster aid is a topic which should be expanded upon, if there is ever to be a solution to the created problem of aid handout dependence.

The more social data that is available, the more holistic understanding the modeler will have. Residents clearly do not mind living within the flood zone, so perhaps the focus of a future computer simulation would not be to delineated hazard zones, but rather identify "safer" areas within these same zones, or designate meeting points which would make evacuation simpler if the flood gets out of hand.

Ideally, my results and the results of future work can be used by researchers for grant organizations, when deciding how to repartition ways in which aid money is spent.

\section{Conclusions}

In the case of flood hazards in El Borbollón, there are many factors which contribute to the difficulty of the situation. Both the hydrology of the basin and the community's attitude towards the lagoon are complexly linked. Despite a small sample size and only exploratory social data, we can see that there is value in using this multi-pronged approach to analyzing the situation. 
Even with very few data points to constrain the simulation, a worthwhile model of past floods can be created. Based on historical flood delineation maps, planning for future flooding events is possible. However, it turns out every member of the community already knows what the flooded lagoon will look like. Although no well-defined hazard zonation maps exist, local residents carry in their memories the experience of repeated flooding events, which gives them a better sense of flood risks than any computer program possibly could.

Despite a less than expected usefulness to community members in the short term, there are many other instances and actors who could find the results of the simulation important. There are many layers of society and science involved in managing a flood and developing a reliable system of predictability by which government and NGOs can organize their resources for aid and for preparation and prevention.

Clearly the near-regular flooding in El Borbollón and the local reaction to the high water levels does not fit the traditional notion of a natural disaster. It has become a routine disaster. But what would be the effects of cutting aid? The situation has become increasingly complex as aid continues to be delivered into the community on a almost yearly cycle. The adaptation and culture of dependency created in the past decades of flooding have coupled this community's fate to that of the Laguna El Jocotal.

So long as the sensationalism of photos and videos from the flooding affects public reaction and inspires continuous aid donations, it is unrealistic to assume the community's tendencies towards aid will change. This is especially worrisome as there will be dire effects to grooming the next generation of inhabitants to consider living with floods as normal. This form of income is definitely not sustainable. Already some NGOs have stopped coming to the community because they have realized the extent to which some locals were capitalizing on their organization's limited resources.

Clearly policy makers, government scientists, aid workers, NGOs, and anyone else involved in disaster aid relief needs a different framework for deciding how to best aid communities in need. There will always be a need for the immediate availability of bare essentials such as food and water, but an assessment of the local point of view - the social perspective - should be considered the norm for each individual location and disaster.

The following is a list of suggestions for policy makers, government scientists, aid workers, and aid organizations:

1- Distribute aid through multiple vectors. Do not rely on single points of contact in communities but rather through as large a network as possible. Find local workers through trusted sources (school teachers, co-op leaders, any sort official, etc.).

2- Focus money more heavily on health issues. This way aid money is guaranteed to make a difference, regardless of the status of the disaster. Local health services are best positioned to deal with these concerns, and they should 
be better prepared and equipped to do so. When dealing with floods, for example, set aside money to spray for mosquitoes.

3- Do not waste money on unnecessary aspects of the disaster response. Large scale flooding in El Borbollón does not require a shelter, for example. Use social data from past events to recognize this, and use the money for a different and more applicable part of the disaster response.

4- Create a partnership model for aid organizations acting locally, so as to eliminate overlap in aid hand-outs, and provide the appropriate assistance to all those who need it.

5- During the post-disaster clean-up and rebuilding phase, employ affected locals to help with labor, at once creating jobs for the most needy and stimulating the local economy.

6- Create educational programs for local school children discussing all the hazards involved with floods (water and fish contamination, increased respiratory illnesses due to dampness, increase in mosquito borne illnesses, etc.). Work with local teachers and community members to make sure the curriculum is attuned to local cultural beliefs regarding the hazard.

7- Raise public awareness on appropriate land use management strategies.

8- Restrict the building of new residence structures within a specified flood zone, and enforce it.

9- Continue social research efforts at a community level. Important insight is gained through interviews and discussions with the community members.

It is very likely that similar situations exist within and, probably to a greater extent, outside of El Salvador. Ultimately, natural hazards are not likely to decrease in the foreseeable future. A sustained effort to minimize risk, reduce vulnerability, increase local capacity, and effectively respond to disasters is needed. The systematic inclusion of social data combined with computer modeling seems the best way to achieve this. 


\section{References}

Akan, O. A. (1993). Urban stormwater hydrology: a guide to engineering calculations. CRC Press.

Alley, W. M. (1984). On the treatment of evapotranspiration, soil moisture accounting, and aquifer recharge in monthly water balance models. Water Resources Research, 20(8), 1137-1149.

Anderson, M., \& Woodrow, P. (1998). Rising from the ashes. Boulder: Lynne Rienner Publishers.

Anderson, M. L., Chen, Z. Q., Kavvas, M. L., \& Feldman, A. (2002). Coupling HECHMS with atmospheric models for prediction of watershed runoff. Journal of Hydrologic Engineering, 7(4), 312-318.

Barnes, J. H. (1984). Cognitive biases and their impact on strategic planning. Strategic Management Journal, 5(2), 129-137.

Benítez, M., Cabrera, E., Chica, N. I., Echeverría, E., Escalante, L. D., Figueroa de Tosbar, M., \& Rosales, N. (1999). Los recursos silvestres y la gente: lecciones aprendidas en un proceso de aprovechamiento sostenible. Los recursos silvestres y la gente: lecciones aprendidas en un proceso de aprovechamiento sostenible, Laguna el Jocotal (El Salvador).

Beven. (October 6, 2011). Tropical Weather Outlook. National Oceanic and Atmospheric Administration. National Hurricane Center. Available online at http://www.nhc.noaa.gov/archive/gtwo/epac/201110070129/index.php?basin= epac\&current_issuance $=201110070129$

Brennan. (October 12, 2011). Tropical Depression Twelve-E Advisory. National Oceanic and Atmospheric Administration. National Hurricane Center. Available online at http://www.nhc.noaa.gov/archive/2011/ep12/ep122011.public.001.shtml?

Cartagena, R., Olmos, R., López, D. L., Soriano, T., Barahona, F., Hernández, P. A., \& Pérez, N. M. (2004). Diffuse soil degassing of carbon dioxide, radon, and mercury at San Miguel volcano, El Salvador. Geological Society of America Special Papers, 375, 203-212.

Central Intelligence Agency. (2014). El Salvador. In The World Factbook. Retrieved from https://www.cia.gov/library/publications/the-worldfactbook/graphics/locator/cam/es_large_locator.gif 
Cepal.org. (2011). CEPAL evalúa costos de daños ocasionados por lluvias en América Central | Comunicado de prensa | Comisión Económica para América Latina y el Caribe. Available online at http://www.cepal.org/es/comunicados/cepalevalua-costos-de-danos-ocasionados-por-lluvias-en-america-central

Cho, Y. (2014). Distributed rainfall-runoff simulation using radar rainfall data (NEXRAD) in the HEC-HMS.

Chesner, C. A., Pullinger, C. R., \& Escobar, C. D. (2004). Physical and chemical evolution of San Miguel volcano, El Salvador. Geological Society of America Special Papers, 375, 213-226.

Chu, X., \& Steinman, A. (2009). Event and continuous hydrologic modeling with HEC-HMS. Journal of Irrigation and Drainage Engineering, 135(1), 119-124.

Cutter, S., Barnes, L., Berry, M., Burton, C., Evans, E., Tate, E., \& Webb, J. (2008). A place-based model for understanding community resilience to natural disasters. Global Environmental Change, 18(4), 598-606. doi:10.1016/j.gloenvcha.2008.07.013

Dilley, M., Chen, R. S., Deichmann, U., Lerner-Lam, A. L., Arnold, M., Agwe, J., Buys, P., Kjekstad, O., Lyon, B., and Yetman, G. (2005). Natural Disaster Hotspots: A Global Risk Analysis. The World Bank Hazard Management Unit, Washington, DC, 132.

Dash, N., \& Gladwin, H. (2007). Evacuation decision making and behavioral responses: Individual and household. Natural Hazards Review, 8(3), 69-77.

Flint, C. G., \& Luloff, A. E. (2005). Natural resource-based communities, risk, and disaster: An intersection of theories. Society and Natural Resources, 18(5), 399-412.

Ford, D., Pingel, N., \& DeVries, J. (2008). HEC-HMS Hydrologic Modeling SystemApplications Guide. US Army Corps of Engineers-Hydrologic Engineering Center. USA.

Fritz, C. E., \& Marks, E. S. (1954). The NORC studies of human behavior in disaster. Journal of Social Issues, 10(3), 26-41.

GFDRR (Global Facility for Disaster Reduction and Recovery). (2011). Disaster Risk Management in Central America : GFDRR Country Notes El Salvador. 20.

Google Earth Pro 7.1.1.1580. (2015b). (April 9, 2013). Eastern region, El Salvador. $13^{\circ} 28^{\prime} 02.66^{\prime} \mathrm{N}, 88^{\circ} 06^{\prime} 12.50^{\prime \prime} \mathrm{W}$, Eye alt $90 \mathrm{mi}$. Map data: Google, 
CNES/Astrium, DigitalGlobe. International Borders layer. Available online at http://www.google.com/earth/index.html. Accessed January 10, 2015.

Google Earth Pro 7.1.1.1580. (2015b). (April 8, 2014). El Borbollón region, E1

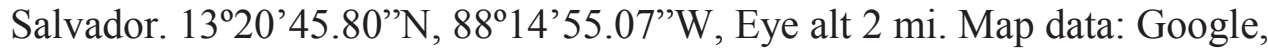
$\mathrm{CNES} /$ Astrium, DigitalGlobe. Available online at http://www.google.com/earth/index.html. Accessed January 10, 2015.

Hamby, D. M. (1995). A comparison of sensitivity analysis techniques. Health Physics, 68(2), 195-204.

Heath, S. E., Kass, P. H., Beck, A. M., \& Glickman, L. T. (2001). Human and petrelated risk factors for household evacuation failure during a natural disaster. American Journal of Epidemiology, 153(7), 659-665.

Hoffmann, S., \& Oliver-Smith, A. (2002). Catastrophe and Culture: The Anthropologie of Disaster.

IFRC (International Federation of Red Cross and Red Crescent Societies). (2013). Emergency Appeal, El Salvador: Tropical Depression 12-E. (Report No. MDRSV004). Retrieved from http://reliefweb.int/sites/reliefweb.int/files/resources/el-salvador-ifrc26092013.pdf

IFRC (International Federation of Red Cross and Red Crescent Societies). (2014). World Disasters Report 2014: Focus on Culture and Risk. Geneva: IFRC.

Jonkman, S. N., Bočkarjova, M., Kok, M., \& Bernardini, P. (2008). Integrated hydrodynamic and economic modelling of flood damage in the Netherlands. Ecological economics, 66(1), 77-90.

Kimberlain, T. B. (2012). Tropical Cyclone Report, Tropical Depression Twelve-E 12 October 2011. National Oceanic and Atmospheric Administration, National Hurricane Center. Available online at http://www.nhc.noaa.gov/data/tcr/EP122011_Twelve-E.pdf. Accessed February 15, 2015.

Knebl, M. R., Yang, Z. L., Hutchison, K., \& Maidment, D. R. (2005). Regional scale flood modeling using NEXRAD rainfall, GIS, and HEC-HMS/RAS: a case study for the San Antonio River Basin Summer 2002 storm event. Journal of Environmental Management, 75(4), 325-336.

Knight, F. H. (1921). The meaning of risk and uncertainty. F. Knight. Risk, Uncertainty, and Profit. Boston: Houghton Mifflin Co, 210-235. 
Komar, O. (2002). Priority conservation areas for birds in El Salvador. Animal Conservation, 5(3), 173-183. doi:10.1017/s1367943002002238

Lugeri, N., Kundzewicz, Z. W., Genovese, E., Hochrainer, S., \& Radziejewski, M. (2010). River flood risk and adaptation in Europe - assessment of the present status. Mitigation and adaptation strategies for global change, 15(7), 621-639.

MARN (Ministerio de Medio Ambiente y Recursos Naturales). (2004). Plan de manejo del área natural del complejo del Jocotal. San Salvador, El Salvador.

Mendis, S., Mills, S., \& Yantz, J. (2003). Building community capacity to adapt to climate change in resource-based communities. Prepared for the Canadian Forest Service.

Mirza, M. M. Q. (2003). Climate change and extreme weather events: can developing countries adapt?. Climate policy, 3(3), 233-248.

Moliere, D. R. (2002). Baseline hydrology characteristics of the Ngarradj catchment, Northern Territory. Supervising Scientist.

NRCS (National Resources Conservation Service). (2004). National engineering handbook, Part 630 hydrology, USDA, Washington, DC.

O'Connell, P. E., \& Todini, E. (1996). Modelling of rainfall, flow and mass transport in hydrological systems: an overview. Journal of Hydrology, 175(1), 3-16.

Oleyiblo, J. O., \& Li, Z. J. (2010). Application of HEC-HMS for flood forecasting in Misai and Wan'an catchments in China. Water Science and Engineering,3(1), 14-22.

Oliver-Smith, A. (1999). What is a disaster? Anthropological perspectives on a persistent question (pp. 18-34). New York: Routledge.

Paton, D. (2006a). Disaster resilience: building capacity to co-exist with natural hazards and their consequences. Disaster resilience: An integrated approach, 3-10.

Paton, D. (2006b). Disaster resilience: integrating individual, community, institutional and environmental perspectives. Disaster resilience: An integrated approach, 320 .

Paton, D., Smith, L., Daly, M., \& Johnston, D. (2008). Risk perception and volcanic hazard mitigation: Individual and social perspectives. Journal of Volcanology and Geothermal Research, 172(3), 179-188. 
Pearce, L. (2003). Disaster management and community planning, and public participation: how to achieve sustainable hazard mitigation. Natural hazards,28(2-3), 211-228.

Peduzzi, P., Dao, H., Herold, C., \& Mouton, F. (2009). Assessing global exposure and vulnerability towards natural hazards: the Disaster Risk Index.Natural Hazards and Earth System Science, 9(4), 1149-1159.

Peters, J. C. (1998). HEC-HMS Hydrologic Modeling System: User's Manual. US Army Corps of Engineers, Hydrologic Engineering Center.

Ramsar.org. (2015). Area Natural Protegida Laguna del Jocotal | Ramsar. Retrieved 23 March 2015, from http://www.ramsar.org/area-natural-protegida-lagunadel-jocotal

Renderos, R., Matus, A., Magaña, M. I., Tenorio, J., \& Cubías, M. (2013).

"Geochemical Surveying and Conceptual Model of Chilanguera Geothermal System, El Salvador."

Sabol, G. V. (1988). Clark unit hydrograph and R-parameter estimation. Journal of Hydraulic Engineering, 114(1), 103-111.

Saunders, W. (1999, July). Preparation of DEMs for use in environmental modeling analysis. In ESRI User Conference (pp. 24-30).

Schellekens, J., Bruijnzeel, L. A., Scatena, F. N., Bink, N. J., \& Holwerda, F. (2000). Evaporation from a tropical rain forest, Luquillo Experimental Forest, eastern Puerto Rico. Water Resources Research, 36(8), 2183-2196.

Singh, V. P., \& Woolhiser, D. A. (2002). Mathematical modeling of watershed hydrology. Journal of hydrologic engineering, 7(4), 270-292.

Slovic, P. (1987). Perception of risk. Science, 236(4799), 280-285.

Slovic, P., Finucane, M. L., Peters, E., \& MacGregor, D. G. (2004). Risk as analysis and risk as feelings: Some thoughts about affect, reason, risk, and rationality. Risk analysis, 24(2), 311-322.

Smith, B. W., \& Freedy, J. R. (2000). Psychosocial resource loss as a mediator of the effects of flood exposure on psychological distress and physical symptoms. Journal of Traumatic Stress, 13(2), 349-357.

Tralli, D. M., Blom, R. G., Zlotnicki, V., Donnellan, A., \& Evans, D. L. (2005). Satellite remote sensing of earthquake, volcano, flood, landslide and coastal 
inundation hazards. ISPRS Journal of Photogrammetry and Remote Sensing, 59(4), 185-198.

SNET (Servicio Nacional de Estudios Territoriales). (2015). "Unpublished rainfall data from San Miguel, El Salvador."

UN (United Nations). (2015). World Statistics Pocketbook. Retrieved 9 March 2015, from http://data.un.org/CountryProfile.aspx?crName=EL\%20SALVADOR

United States Army Corps of Engineers, Hydrologic Engineering Center (USACEHEC). (2000). Hydrologic Modeling System HEC-HMS Technical Reference Manual

United States Army Corps of Engineers, Hydrologic Engineering Center (USACEHEC). (2010). Hydrologic Modeling System HEC-HMS Technical Reference Manual

UNCEPAL (United Nations Comisión Económica para América Latina y el Caribe). (2012). Resumen Regional Del Impacto de la Depresión Tropical 12-E en Centroamérica. Cuantificatión de Daóos y Pérdidas Sufridos por los Países de la Región en el Mes de Octubre de 2011. Available online at http://www.cepal.org/publicaciones/xml/3/46593/2012-012-

Depresión_Tropical-12-E.L.1060-Parte_1.pdf. Accessed February 15, 2015.

UNDAC (United Nations Disaster Assessment and Coordination). (2010). Evaluación de la Capacidad Nacional para la Respuesta a Emergencias. Retrieved from http://www.gfdrr.org/sites/gfdrr.org/files/DRM_CENTRAL_AMERICA.pdf

Westerman, D. A., \& Clark, B. R. (2013). Simulation of the June 11, 2010, Flood Along the Little Missouri River near Langley, Arkansas, Using a Hydrologic Model Coupled to a Hydraulic Model. US Geological Survey Scientific Investigations Report, (5056), 35.

Wildavsky, A., \& Dake, K. (1990). Theories of risk perception: Who fears what and why? Daedalus, 41-60. 


\section{Appendix 1 - Simulation methods in HEC-HMS}

\begin{tabular}{|c|c|c|}
\hline \multirow{26}{*}{$\begin{array}{l}\overline{0} \\
\frac{0}{0} \\
\frac{0}{2} \\
. \frac{5}{n} \\
\bar{D}\end{array}$} & \multirow{8}{*}{ Loss Method } & Green \& Ampt \\
\hline & & Initial/Constant \\
\hline & & SCS Curve Number \\
\hline & & Gridded Curve Number \\
\hline & & Deficit/Constant \\
\hline & & Soil Moisture Accounting (SMA) \\
\hline & & Gridded SMA \\
\hline & & Smith Parlange \\
\hline & \multirow{7}{*}{$\begin{array}{l}\text { Transform } \\
\text { Method }\end{array}$} & Clark Unit Hydrograph \\
\hline & & Kinematic Wave \\
\hline & & ModClark \\
\hline & & SCS Unit Hydrograph \\
\hline & & Snyer's Unit Hydrograph \\
\hline & & User specified S-graph \\
\hline & & User specified Unit Hydrograph \\
\hline & \multirow{5}{*}{$\begin{array}{l}\text { Baseflow } \\
\text { Method }\end{array}$} & Bounded Recession \\
\hline & & Constant Monthly \\
\hline & & Linear Reservoir \\
\hline & & Nonlinear Boussinesq \\
\hline & & Recession \\
\hline & \multirow{6}{*}{$\begin{array}{l}\text { Routing } \\
\text { Method }\end{array}$} & Kinematic Wave \\
\hline & & Lag \\
\hline & & Modified Puls \\
\hline & & Muskingum \\
\hline & & Muskingum-Cunge \\
\hline & & Straddle Stagger \\
\hline \multirow{7}{*}{ 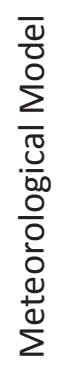 } & \multirow{7}{*}{$\begin{array}{c}\text { Precipitation } \\
\text { Method }\end{array}$} & Frequency Storm \\
\hline & & Gage Weights \\
\hline & & Gridded Precipitation \\
\hline & & Inverse Distance \\
\hline & & SCS Storm \\
\hline & & Specified Hyetograph \\
\hline & & Standard Project Storm \\
\hline
\end{tabular}

Table 1. Summary of simulation method options offered in HEC-HMS. 
Appendix 2 - Soil infiltration capacity values

\begin{tabular}{|l|c|}
\hline Soil Type & $f_{o}$ (in/hr) \\
\hline Dry sandy soils with little or no vegetation & 5.0 \\
\hline Dry loam soils with little or no vegetation & 3.0 \\
\hline Dry clay soils with little or no vegetation & 1.0 \\
\hline Dry sandy soils with dense vegetation & 10.0 \\
\hline Dry loam soils with dense vegetation & 6.0 \\
\hline Dry clay soils with dense vegetation & 2.0 \\
\hline Moist sandy soils with little or no vegetation & 1.7 \\
\hline Moist loam soils with little or no vegetation & 1.0 \\
\hline Moist clay soils with little or no vegetation & 0.3 \\
\hline Moist sandy soils with dense vegetation & 3.3 \\
\hline Moist loam soils with dense vegetation & 2.0 \\
\hline Moist clay soils with dense vegetation & 0.7 \\
\hline
\end{tabular}

Table 2. Soil infiltration capacity values based on soil type. Taken from Akan (1993). 


\section{Appendix 3 - Preliminary survey}

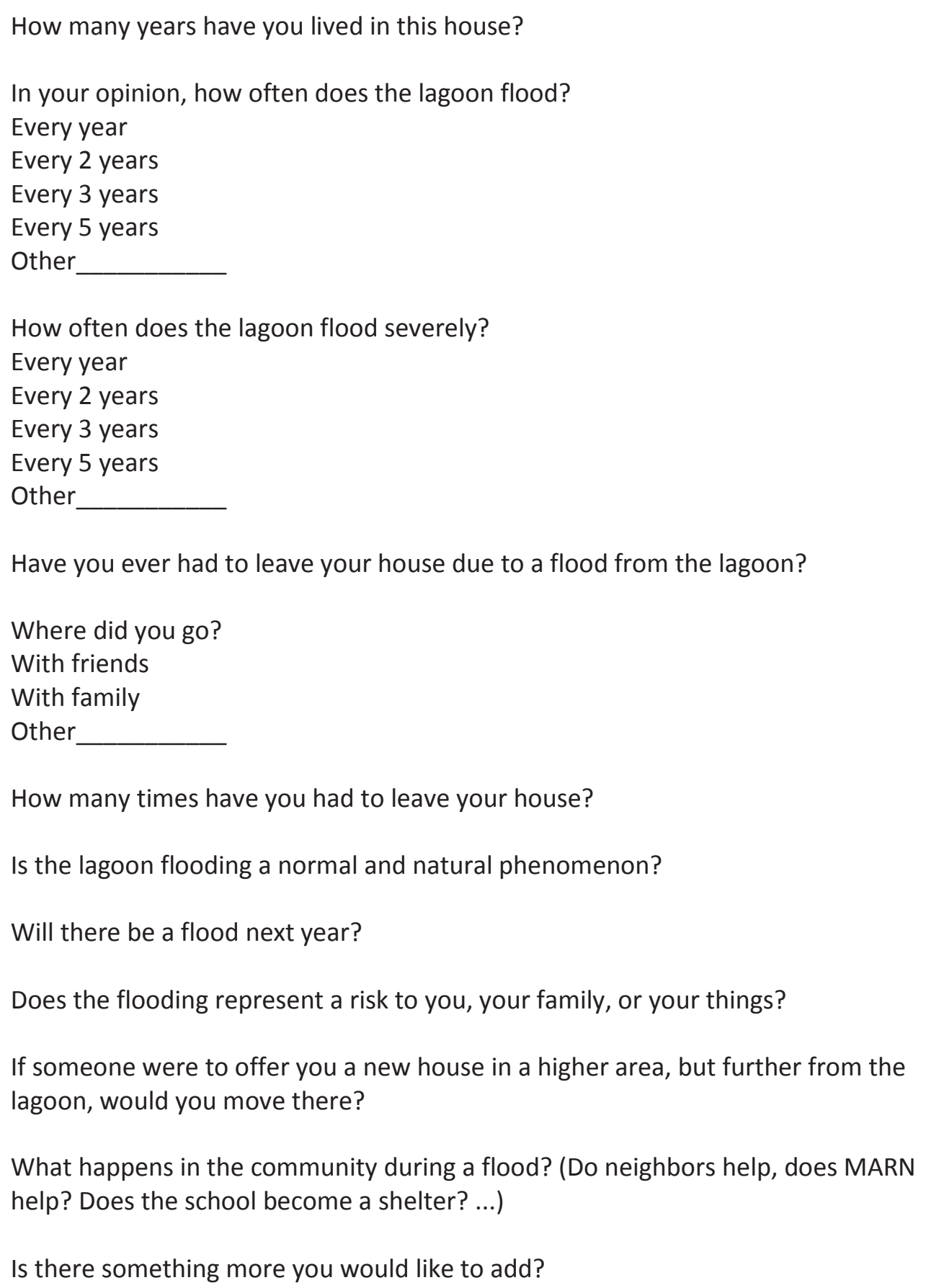

Figure 16. Questionnaire used in survey of local residents. 


\section{Appendix 4 - Interview details}

Interview \#1:

August 19, 2013.

10:30 AM - 12:20 PM.

Male, in his 40s.

Moved to the community in 1990.

Interviewee is a prominent local land owner, farmer, and raiser of livestock. He employs some of the community's youth as hands on his land, and owns much of the land at the edge of the lagoon and town.

As a community leader living close to the lagoon, this interviewee is in a position to answer questions about the regularity of living with floods.

Interview \#2:

August 19, 2013.

12:45 PM - 1:45 PM.

3 Males, all in their 30s or 40s, all have lived their entire lives within the community. This was a group interview with 3 official Park Rangers. These rangers, who are employed federally by the Ministry of the Environment and Natural Resources (MARN), are tasked with monitoring biodiversity studies, poaching, illegal fishing, deforestation and everything else within the National Protected Area.

Interview \#3:

August 28, 2013.

3:30 PM - 4:25 PM.

Male, 58 years old.

Moved to community as a small child in 1957.

$\mathrm{He}$ is a community leader and former local business owner. He lives in the zone frequently affected by flooding, and is head of the local Civil Protection branch (which is tasked with managing and coordinating with the representatives of NGOs and foreign governments to provide assistant to victims of natural disasters).

Interview \#4:

August 30, 2013.

12:30 PM - 1:45 PM.

Male, appears to be in his early 60s.

Well respected community leader, former local business owner, former official Park Ranger. Used to live in low lying area of community, but moved to higher elevation after a large flooding event. He was also my landlord and host father for the 24 months I lived in the community. 


\section{Appendix 5 - Permission to use copyrighted materials}

Figure 1 is a regional map of Central America, which was adapted and edited by the author. The original map comes from the Central Intelligence Agency's The World Factbook, which is in the public domain.

Permission can be found plainly written on the The World Factbook's webpage, available at https://www.cia.gov/library/publications/the-world-

factbook/docs/contributor_copyright.html.

Figure 2 and Figure 3 are satellite images from the Google Earth Pro, which have been labeled by the author. They follow all the guidelines set by Google for using their satellite imagery, in that they were not changed in any way and they including proper attribution in the figure caption. These guidelines are viewable on the webpage titled "Permission Guidelines for Google Maps and Google Earth", available at http://www.google.com/permissions/geoguidelines.html.) 